\title{
¡Vaya Valla! \\ El yeísmo en el español de Valencia ${ }^{1}$
}

\author{
José R. Gómez Molina ${ }^{2}$ \\ $M^{a}$. Begoña Gómez Devís \\ Universitat de València
}

\begin{abstract}
Resumen
En los últimos años, el fenómeno del yeísmo ha sido abordado desde diferentes perspectivas; una de ellas es la sociolingüística, a la que nuestro trabajo pretende contribuir. El objetivo de este artículo es presentar cómo evoluciona el proceso fonético de deslateralización del fonema $/ K /$ a favor de $/ \mathrm{j} /$ en el castellano de la comunidad de habla bilingüe de Valencia y su área metropolitana. Tradicionalmente se ha señalado que Valencia mantenía la diferenciación entre la lateral y fricativa palatales, pero estudios recientes dan cuenta de la introducción y expansión del yeísmo en determinadas comarcas bilingües de la Comunidad Valenciana. En el análisis sociolingüístico realizado actúan grupos de factores lingüísticos, estilísticos y sociales como variables independientes; dicho análisis se ha complementado con un estudio de fonética perceptiva. Los resultados obtenidos nos
\end{abstract}

\footnotetext{
1 Esta investigación forma parte del proyecto financiado por el Ministerio de Ciencia y Tecnología Estudio sociolingüistico del español de Valencia (Ref. HUM2004-06052-C06-01 y Ref. HUM2007-65602-C07-01) y subvencionado con Fondos FEDER.

2 Para correspondencia, dirigirse a: José Ramón Gómez Molina ( jose.r.gomez@uv.es) o a Begoña Gómez Devís (m.begona.gomez@uv.es), Departamento de Filología Española, Facultad de Filología, Traducción y Comunicación, Universidad de Valencia, Avda. de Blasco Ibáñez, 32, 46010 Valencia, España.
} 
permiten establecer en qué estadio se encuentra este fenómeno en nuestra comunidad (distinción fonemática, yeísmo con variación, yeísmo consolidado o yeísmo rehilado), qué hablantes actúan como líderes del proceso de deslateralización y cuál es la percepción subjetiva que tienen los hablantes de este fenómeno.

Palabras clave: variación fonética, yeísmo, percepción subjetiva, comunidad de habla bilingüe.

\title{
Vaya Valla! The PhenOMENON OF "YeÍSmo" In ORAL SPanish IN VALENCIA
}

\begin{abstract}
In the last few years, the notion of yeismo has been approached from different perspectives; one of them is Sociolinguistics, the field in which the contribution of the present work is embedded. The aim of this article is to present the evolution of the phonetic process of delateralization of the phoneme $/ K /$ in favour of $/ \mathrm{j} /$ in the use of Spanish by speakers in the bilingual speech community in Valencia and the sorrounding areas. From a traditional perspective, it was claimed that speakers in Valencia maintained the differentiation between the lateral and fricative palatals. However, more recent studies focus on the introduction and expansion of yeismo in particular areas in the Valencian region. For this sociolinguistic study a series of linguistic, stylistic and social factors have been established as independent factors. The study has been complemented with an analysis of perceptual phonetics. The results obtained in the study allow us to specify the stage at which this phenomenon is found in our region (phonematic distinction, yeismo with variation, consolidated yeismo or yeismo rehilado), who the speakers that act as leaders in the process of delateralization are and what the subjective perception speakers have of this phenomenon is.
\end{abstract}

Keywords: Phonetic variation, yeismo, subjective perception, bilingual speech community.

Recibido: 24/02/2016

Aceptado: 01/07/2016 


\section{INTRODUCCIÓN}

Son varios los estudios teóricos y empíricos sobre el proceso de desfonologización que afecta a la distinción entre las consonantes palatal lateral $/ \mathrm{K} /$ y palatal central fricativa $/ \mathrm{j} / \mathrm{del}_{\text {español }}{ }^{3}$; entre ellos y sin ánimo de exhaustividad: Guitarte (1983), Martínez Martín (1983), Molina Martos (1997, 2013), Penny (2000, 2004), Martín Butragueño (2002, 2012, 2013), Villena (2003), Moreno Fernández (2004), Martínez Celdrán y Martínez Planas (2007), Torres et al. (2013), Caravedo (2013), Dubert (2013) y Rost Bagudanch $(2013,2014)$. Este fenómeno de confusión entre la consonante lateral palatal y una consonante palatal tradicionalmente caracterizada como fricativa es conocido como yeísmo; así se define: "la pronunciación de la $l l$ como y: cabayo, yave, gayina por caballo, llave, gallina, y se produce por la relajación articulatoria de la $l l$ " (Navarro Tomás 1990: 134) o "la distinción entre las dos palatales desaparece; este fenómeno de desfonologización se conoce con el nombre de yeísmo" y se debe a un proceso de lenición por el que "la lengua pierde su contacto con la parte central y anterior del paladar y sobreviene la articulación central" (Quilis 1993: 315).

Se trata de un hecho que afecta al esquema fonológico de nuestra lengua puesto que confunde y fusiona dos fonemas originalmente distintos. Es cierto que esta confluencia de alófonos tiene un origen bajomedieval (Frago 1993, Ariza 1994, Cano Aguilar 2004, Penny 2004) y como señala Martínez Martín (1983: 80), parece legítimo plantear la hipótesis de la existencia de un estado de latencia del fenómeno yeísta si tenemos en cuenta los contactos que han tenido históricamente las realizaciones $[K],[j],[j],[3],\left[\mathrm{d}_{3}\right]$. Pero el rápido desarrollo de este proceso de deslateralización a favor de la palatal central durante el siglo XX es tal que "su presencia en amplias zonas, así como su creciente expansión, hacen del yeísmo un fenómeno aceptado en la norma culta" (RAE 2005: 682).

\footnotetext{
Dada la existencia de diferentes alfabetos fonéticos, en este trabajo se emplea el Alfabeto Fonético Internacional (International Phonetic Association 2005). Si lo comparamos con la revisión de Martínez Celdrán y Fernández Planas (2007) observamos algunas diferencias: $[K]$ aproximante lateral palatal (AFI), aproximante lateral (Martínez y Fernández 2007: 170) / [j] fricativa palatal (AFI), [j] aproximante espirante (Martínez y Fernández 2007: 170) / [j] aproximante palatal (AFI). Para Martínez y Fernández (2007: 62) "los segmentos [j] y [j] son diferentes y, en cambio, según el AFI hay que llamarlos a ambos consonantes aproximantes palatales sonoras".
} 
La distinción fonológica original va desapareciendo porque son elementos muy próximos que forman una oposición aislada y débil, pues no se integra en un sistema de palatales tan equilibrado como otros, y porque muestra un escaso rendimiento funcional ${ }^{4}$, tal como señalan varios autores (Alarcos 1971: 279, Martinet 1974: 82); además, también contribuye a ello que la articulación de la palatal fricativa [j] requiere menos esfuerzo que la de la lateral palatal $[\kappa]$. Por otra parte, el yeísmo tiene carácter urbano:

La innovación yeísta en España ha seguido dos líneas de difusión, una urbana y otra rural, de manera que su progresión geográfica no ha sido lineal. La pérdida de la oposición fonológica de las palatales / $\chi /$ y / j/ se ha cumplido primero en las ciudades y después en el entorno rural sobre el que estas ejercen su influencia económica (Molina Martos 2013: 93).

Dado el interés que este fenómeno de variación y cambio fonológico representa en el dinamismo del español peninsular, los equipos que integran el proyecto panhispánico PRESEEA ${ }^{5}$ han considerado relevante su análisis. Por ello, el objetivo de este artículo es informar sobre el estado actual de la oposición fonológica entre las consonantes palatales sonoras lateral $/ K / \mathrm{y}$ fricativa $/ \mathrm{j} /$ en el español de la comunidad de habla bilingüe castellano-valenciano ${ }^{6}$ de Valencia. Nuestra investigación analiza si se está produciendo algún cambio fonético en la pronunciación de la lateral palatal $[K]$ como palatal fricativa [j] o como aproximante ${ }^{7}$ palatal [j], dado que en nuestra comunidad de habla no se articula el sonido fricativo rehilado sonoro [3].

Tradicionalmente, la comunidad de habla que investigamos era una de las áreas donde se mantenía la distinción fonológica: "En las provincias bilingües de Galicia, Vasconia, Cataluña y Valencia, la diferenciación entre lateral y fricativa palatales, practicada en las propias lenguas locales, se aplica también al español" (Navarro Tomás 1964: 720). Sin embargo, algunos estudios recientes (Segura 2003, Moratal 2011) dan cuenta de la

\footnotetext{
4 Son escasos los pares de palabras que se distinguen por la presencia de ambos fonemas: valla(s)/vaya(s), callado/cayado, pollo/poyo, pulla/puya, rallar/rayar, halla(s)/haya(s), olla/ hoya...

Proyecto para el Estudio Sociolingüístico del Español de España y América. Disponible en http://www.preseea.linguas.net.

6 Valenciano, variedad dialectal del catalán propia de la Comunidad Valenciana.

7 Según el modo de articulación, aproximante responde a que el canal por el que pasa el aire es más ancho que en el caso de las fricativas, es decir, hay menos aproximación de los articuladores (dorso de la lengua y paladar).
} 
introducción y avance del yeísmo en determinadas comarcas bilingües de la Comunidad Valenciana. Los resultados de este trabajo permitirán situar en qué estadio de los establecidos por Moreno Fernández (2004: 984-985) se encuentra dicho fenómeno: mantenimiento de la distinción fonemática de las palatales $[K] /[j]$; yeísmo con variación; yeísmo sin restos ya de la lateral y con distintos grados de tensión y adelantamiento, o un aflojamiento que da lugar a un sonido semiconsonántico [j]; y yeísmo con soluciones rehilantes [3].

El objetivo central de la investigación se desglosa en dos objetivos específicos:

1. Conocer el grado de mantenimiento de la distinción fonemática entre las consonantes palatales sonoras lateral $[K]$ y fricativa [j]; también analizar si el aflojamiento articulatorio permite la confluencia con la aproximante palatal sonora [j]. Estos datos de fonética acústica se complementan con un estudio de fonética perceptiva para descubrir la capacidad de los hablantes en la discriminación de rasgos fónicos discretos.

2. Evaluar la situación actual de la deslateralización en el castellano de Valencia desde la perspectiva sociolingüística para conocer si estamos ante un caso de variación estable o se está gestando un proceso de cambio lingüístico.

Asimismo, a partir de los resultados de diferentes estudios sobre este fenómeno y de nuestro conocimiento sobre la comunidad de habla se formulan cuatro hipótesis, que se irán desgranando en el presente trabajo:

Primera. Los grupos generacionales ofrecerán distinto grado de resistencia al debilitamiento o pérdida de la oposición fonológica: mientras los mayores de 55 años diferenciarán ampliamente la articulación de ambos sonidos, los jóvenes irán debilitando dicha oposición. Ello puede contribuir, junto con otras causas, al inicio del cambio fonológico.

Segunda. Dada la aceptabilidad social del fenómeno (RAE 2005: 682), el yeísmo puede ampliar su expansión al ser considerado como factor de prestigio, impulsado por las modas lingüísticas. Y al tratarse de una variante con prestigio social, afectará más a las mujeres que a los hombres.

Tercera. Considerando que los valencianohablantes pronuncian la lateral palatal $[K]$ cuando hablan en catalán (llengua, falla, paella, anell, gallina, pollastre), los hablantes bilingües contribuirán al mantenimiento de la oposición fonológica en esta situación de contacto lingüístico. Además, 
opinamos que el yeísmo en los hablantes bilingües es resultado de una evolución convergente entre ambas lenguas ${ }^{8}$.

Cuarta. Los resultados del cuestionario de fonética perceptiva mostrarán que la distinción entre las palatales sonoras lateral y fricativa no es clara, fruto de la confusión en la discriminación auditiva de los rasgos fónicos comunes y distintos; ello demostrará que el proceso de cambio se inicia por errores de percepción que dan lugar a ambigüedades en la interpretación fonológica y la sustitución a largo plazo de un elemento por otro.

\section{ALGUNAS CONSIDERACIONES EPISTEMOLÓGICAS SOBRE EL YEÍSMO}

Es evidente que el tratamiento de este fenómeno vivo, apreciable también en otras lenguas románicas (italiano, catalán, portugués), puede abordarse desde diferentes perspectivas sean etimológicas, diacrónicas, dialectales, fónicas o sociolingüísticas. En este artículo solo desarrollamos una breve descripción fonológico-fonética y algunas cuestiones de índole sociolingüística que nos permitan encuadrar la variación en un contexto de cambio fonológico, asumiendo que en este marco "la formalización fonológica es útil para describir mejor y solo eso los fenómenos variables" y que "solo la investigación sustantiva arrojará verdaderas luces sobre el problema" (Martín Butragueño (2002: 105).

Si observamos la evolución de las teorías fonológicas, hay que esperar hasta finales del siglo XX para poder tratar los elementos variables desde una perspectiva más flexible. Un ejemplo de ello es la Teoría de la Optimidad (marco TO) (cfr. Guy 1997, Cutillas 2003, Prince y Smolensky 2004), modelo fonológico muy útil para tratar la diversidad lingüística así como la tipología de estrategias utilizadas en las lenguas para ajustarse a los requisitos fonológicos. Esta teoría mantiene que los hechos fónicos de cada lengua responden a un orden universal, que la variación lingüística es posible entre las lenguas, que las restricciones ejercen un papel central, puesto que estas

\footnotetext{
Existen dos opiniones encontradas en cuanto a la explicación de por qué se produce yeísmo en zonas catalanoparlantes: una de ellas, quizás la más extendida, opina que se debe a razones de contacto lingüístico y a razones de prestigio del castellano; otra defiende que se debe a razones propias del sistema lingüístico.
} 
caracterizan los universales, y que las infracciones a dichas restricciones delimitan la marcación, los patrones lingüísticos y la variación.

De acuerdo con este planteamiento, en la variación y cambio fónicos actúan dos tipos de restricciones: las de fidelidad (Faithfulness Constraints) y las de marcación (Markedness Constraints), exigencias del sistema fonológico para garantizar la comunicación y que son esenciales para entender el desarrollo de la fonología pues reflejan la estabilidad de una propiedad en la lengua. Asimismo, la tendencia natural consiste en que los segmentos no marcados emerjan cuando las constricciones de fidelidad dejan de ser dominantes.

Dado que nuestro objeto de estudio ha experimentado una adaptación diacrónica y que no ha afectado a la utilidad comunicativa de los usuarios, podemos considerar que dichas restricciones no son de carácter universal sino que afectan específicamente a una lengua determinada. En esta línea, Morris (1998), atendiendo a la variación estilística del español, establece esas dos familias de restricciones: fidelidad y marcación (también denominadas 'preservación' y 'debilitamiento', respectivamente). Ambas restricciones se contraponen pero lo más interesante en nuestro caso son las secuencias fónicas no marcadas pues reflejan un escaso rendimiento funcional. Como apunta Lindblom (1990), los sonidos no son categorías cerradas e invariables ya que interactúan con los segmentos contiguos; por ello, su realización fonética oscila en un continuum entre la relajación articulatoria (tendencia del hablante al mínimo esfuerzo motor) y la hiperarticulación (garantiza la discriminación del sonido por parte del interlocutor); también Guy y Boberg (1997) señalan que ciertos cambios fónicos cuentan con entornos propicios que los facilitan.

Así pues, analizaremos el proceso de deslateralización de la palatal lateral tomando en consideración la acción del contexto fónico en línea como un contorno probable de generalización probabilística; y para ello se han establecido como factores de análisis la vocal anterior y la posterior considerando que las realizaciones aproximantes aparecen fundamentalmente en posición intervocálica.

En el caso que nos ocupa, el conflicto entre ambas restricciones se resuelve a favor de la deslateralización, pues, de un lado, la pronunciación aproximante requiere un mínimo esfuerzo articulatorio, es decir, favorece la simplicidad y facilita la producción; y de otro, no es necesario maximizar la distintividad por lo que muchos hablantes ya son incapaces de diferenciar estos alófonos en la audición del mensaje. Este proceso de desfonologización, aunque frenado en ocasiones por exigencias del sistema lingüístico y en otras por determinados hablantes, avanza y afecta al catálogo fonemático del español al implicar la desaparición del fonema $/ K /$. 
Otro aspecto de este marco descriptivo que conviene presentar es el análisis acústico de las variantes fónicas. Atendiendo al grado de abertura de los articuladores, la visualización de la estructura formántica nos permitirá distinguir las diferencias significativas en las realizaciones de de los segmentos $[K]$-[j]-[j]. Conviene señalar que Martínez Celdrán y Fernández Planas (2007: 139-141) al analizar el fonema $/ K /$, demuestran con electropalatogramas que el sonido $[K]$ es alveopalatal y no palatal como habían señalado otros autores (Alarcos 1971, Quilis 1993).

Estudios varios de fonética acústica reconocen que la palatal lateral ha ido perdiendo terreno en favor bien de la variante fricativa palatal, bien hacia una consonante de tipo aproximante palatal, bien hacia soluciones rehilantes. Y ante el variado repertorio de alófonos, Rost Bagudanch (2013), resalta la necesaria unificación de los criterios empleados tanto en la representación gráfica como el valor que se les debe dar en cuanto realizaciones fonéticas y apunta, incluso, a la práctica desaparición de las divergencias que permiten la discriminación entre $[K]$ y [j]. Como ya se ha indicado, en esta investigación hemos optado por emplear el AFI (IPA International Phonetic Alphabet 2005 ) en la definición como sonidos y en su representación.

Gráficamente podemos diferenciar la articulación de los dos segmentos clave, $[K]$ y [j], mediante los espectrogramas de banda ancha, imágenes muy utilizadas en fonética acústica y que nos muestran los formantes vocálicos, los ruidos fricativos y otros sonidos. Su eje vertical plasma las frecuencias en $\mathrm{Hz}$ y el eje horizontal representa la cantidad del estímulo (tiempo en segundos), y la intensidad se manifiesta en forma de mayor o menor oscuridad. Ambos segmentos se distinguen entre sí por la mayor duración y mayor intensidad de $[K]$, y por el menor valor del segundo formante y menos armónico para [j]; a su vez, los dos sonidos son menos intensos que las vocales adyacentes. También la trayectoria de los formantes $\mathrm{F}_{1}$ (formante primero) $\mathrm{y}_{2}$ (formante segundo) nos permite seguir las transiciones debidas a las influencias consonánticas': $\mathrm{F}_{1}$ muestra el punto de articulación (palatal) e indica también la sonoridad (intensidad); por su parte, $\mathrm{F}_{2}$ señala el modo de articulación (lateral $[K]$, fricativa [j]). Estos dos primeros formantes son los más relevantes en la percepción de cada sonido; los formantes superiores ponen de manifiesto rasgos individuales del hablante (sexo, edad, estado anímico, condición sociocultural, etc.).

\footnotetext{
9 Los formantes son las líneas de puntitos oscuros en el espectrograma. Pueden observarse cinco líneas que corresponden a cinco formantes, que se ordenan de abajo hacia arriba; así $\mathrm{F}_{1}$ es el más bajo, le sigue $\mathrm{F}_{2} \mathrm{y}$ así sucesivamente.
} 


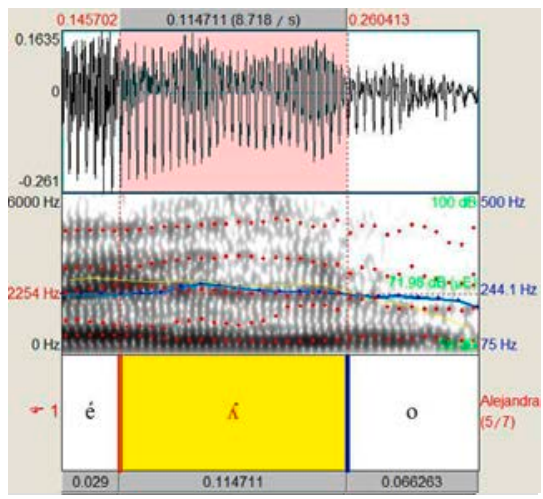

Figura 1. Espectrograma de $[K]$ "con ellos"

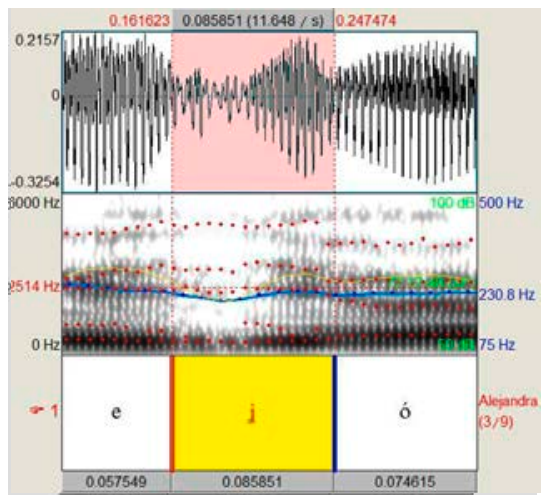

Figura 2. Espectrograma de [j] "que yo recuerde"

En síntesis, el filtro acústico de banda ancha nos proporciona un espectrograma idóneo para mostrar los rasgos de los sonidos, entre ellos, la configuración de los formantes, que nos permite el reconocimiento de las variantes objeto de estudio. Otra cuestión a tener en cuenta es si la sílaba donde aparece el alófono es tónica o átona; en estos casos, según apunta Quilis (1988: 282), $F_{1}$ no presenta diferencia en la frecuencia pero $F_{2}$ y $F_{3}$ mantienen una frecuencia más alta en sílaba tónica que átona. Asimismo, tanto la palatal fricativa como la aproximante significan mayor relajación de los órganos articulatorios y pérdida de intensidad.

Conviene señalar, por otra parte, que mientras la mayoría de autores reconoce que $[K]$ pierde terreno frente a la variante fricativa palatal central [j], Martínez Celdrán y Fernández Planas (2007: 63) señalan que se trata más bien de una consonante de tipo aproximante palatal [j] con estrías típicas de los sonidos armónicos y con un enlace débil de $\vec{F}_{2}$ y $F_{3}$ entre ambas vocales. También estos autores (2007: 134) indican que los sonidos laterales españoles carecen de ruido y, por tanto, son de tipo aproximante; además, poseen formantes más débiles que los de las vocales adyacentes, y ello se observa por el grado de negror en el espectrograma. Todos estos comentarios pueden observarse al visualizar los siguientes espectrogramas, donde tanto las fricativas como las aproximantes ocurren en posición intervocálica ${ }^{10}$ :

10 Los espectrogramas proceden de respuestas de informantes a diferentes fotografías. ¿Qué es esto?: una calle / una paella / un pollo; ante la imagen de la valla antiinmigrantes levantada en Melilla responden: ¡Vaya valla! Los formantes pueden observarse bien en las líneas de puntitos oscuros, bien en las franjas oscuras horizontales. 

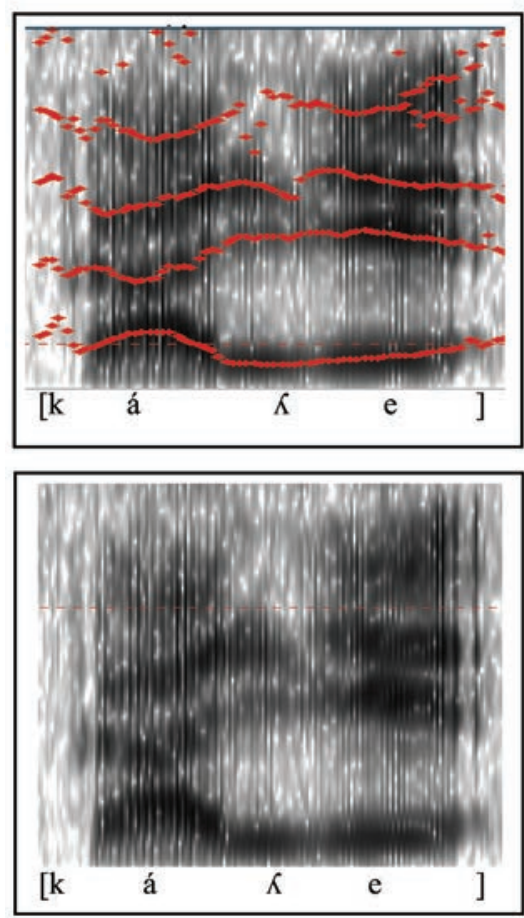

Figura 3. Espectrogramas de /káKe/ con el alófono $[\kappa]$. Pronunciación de un hombre castellanohablante de 62 años

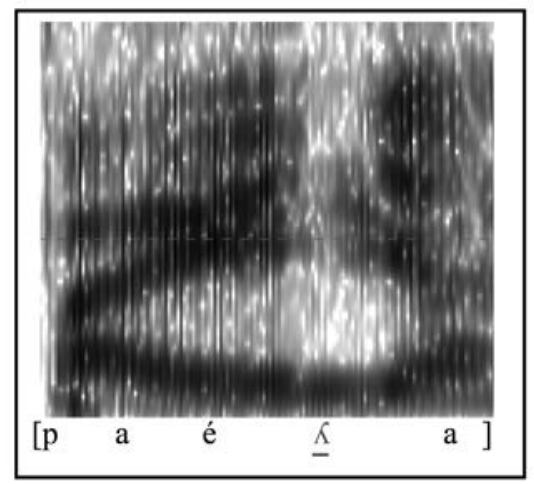

Figura 5. Espectrograma de/paéKa/con el alófono $[K]$. Pronunciación de una mujer bilingüe de 66 años
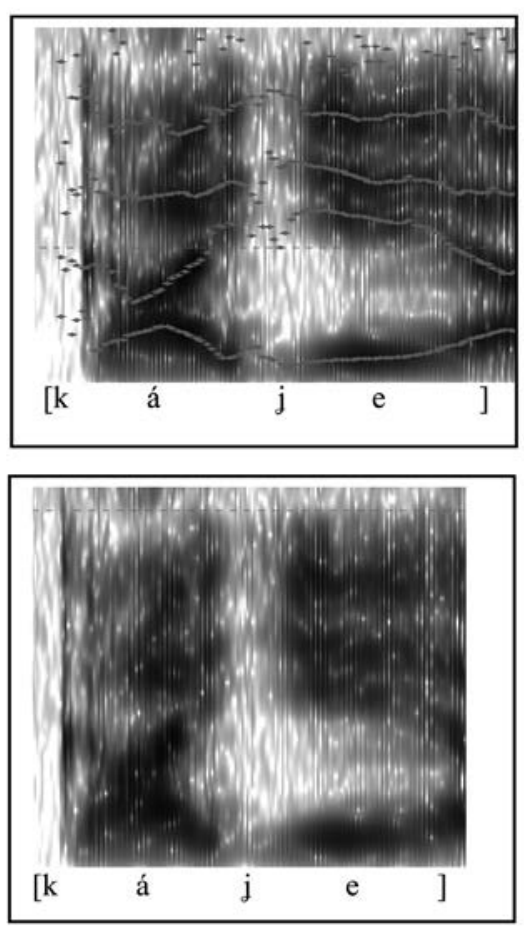

Figura 4. Espectrogramas de /káKe/ con el alófono [j]. Pronunciación de una mujer castellanohablante de 43 años

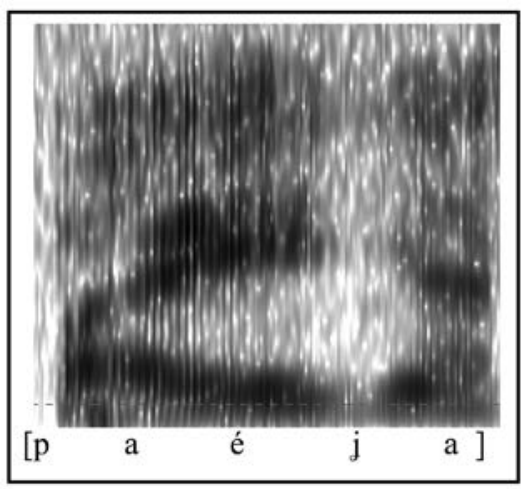

Figura 6. Espectrograma de /paéKa/ con el alófono [j]. Pronunciación de una mujer bilingüe de 26 años 


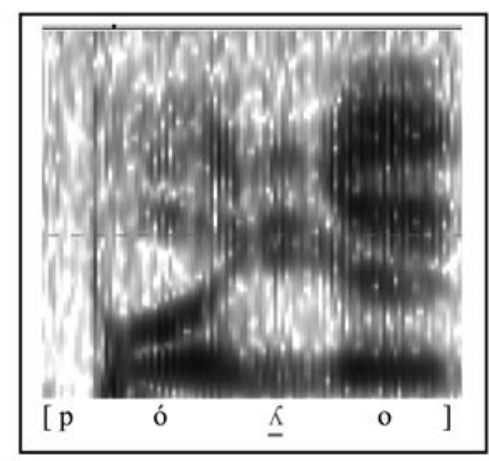

Figura 7. Espectrograma de/póKo/ con el alófono $[\Lambda]$. Pronunciación de un a mujer castellanohablante de 68 años

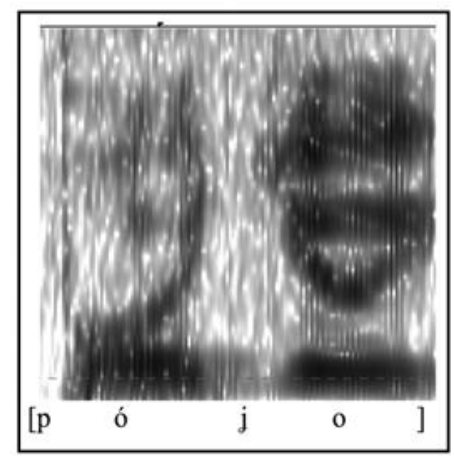

Figura 8. Espectrograma de/pó $/$ o/ con el alófono [j]. Pronunciación de un hombre bilingüe de 26 años

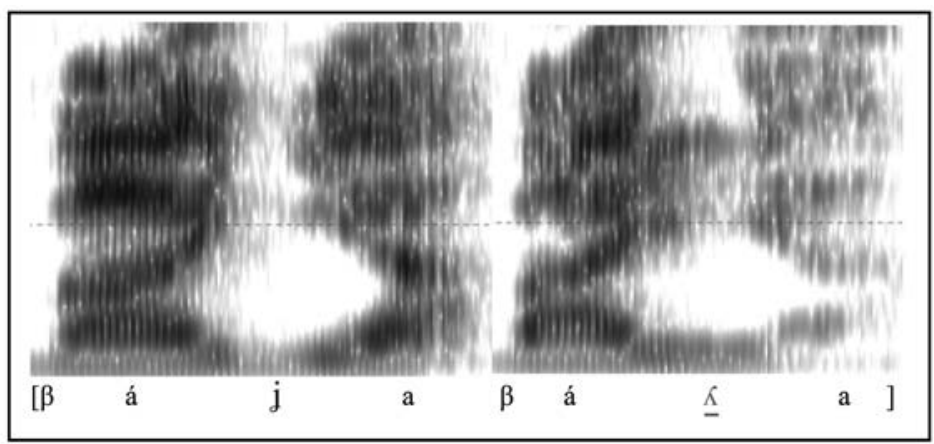

Figura 9. Espectrograma de /bája báKa/ con distinción de alófonos. Pronunciación de un hombre bilingüe de 66 años

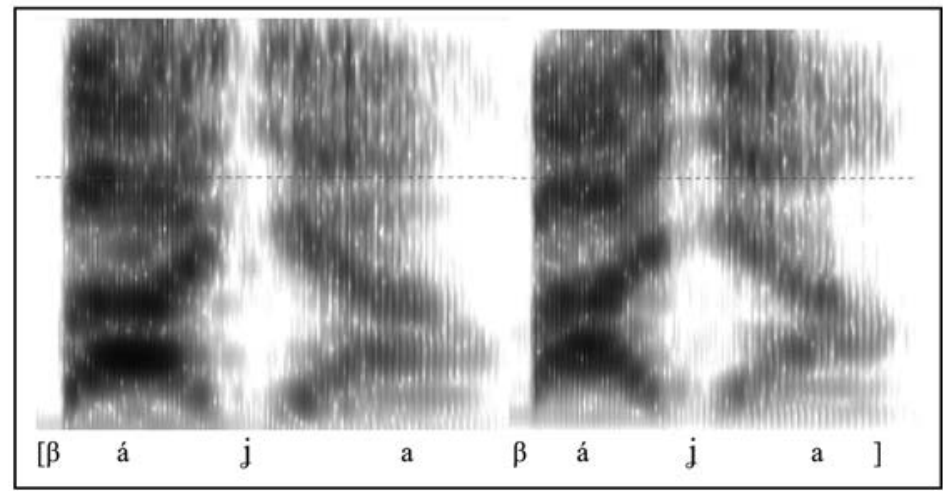

Figura 10. Espectrograma de /bája báKa/ sin distinción de alófonos. Pronunciación de una mujer castellanohablante de 35 años 
Vistas estas cuestiones fonéticas y asumiendo que son consecuencia tanto de una comodidad articulatoria por parte del hablante como de que la comunicación no pierde carga informativa, la sociolingüística cognitiva (Moreno 2012: 146-157) propone que las unidades llamadas fonemas y sus variantes han de interpretarse como categorías sujetas a los patrones del cognitivismo. Y entre las premisas teóricas destacan tres:

- Los sonidos de una lengua no son percibidos del mismo modo por todos los hablantes; algunos de ellos incluso pasan desapercibidos; evidentemente, la percepción de sonidos diferentes [K] - [j] - [j] está estrechamente ligada a la naturaleza, yeísta o no, del receptor de la señal;

- La estructura interna de los fonemas adopta una disposición radial (o lineal) en la que algunos de sus alófonos (variantes) pueden coincidir con los correspondientes a otros fonemas. Desde esa perspectiva, consideramos que la disposición lineal correspondiente a los fonemas objeto de estudio en nuestra comunidad de habla es la representada en el cuadro siguiente, donde $/ K /$ experimenta un proceso de deslateralización que se aproxima a /j/:

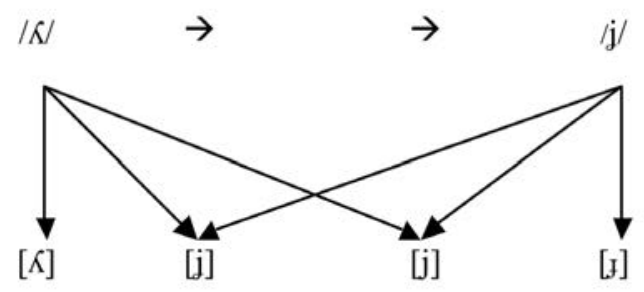

- Por último, las variantes fónicas pueden darse tanto en un nivel de consciencia como en un nivel inconsciente. Por nuestra parte hemos comprobado que hay hablantes que son conscientes de las diferencias fónicas pero pronuncian de forma inconsciente sin diferenciarlas.

Desde esta perspectiva cognitivista, la variación fónica se configura en tres niveles de abstracción: el nivel de esquema (E, lo que el hablante cree que pronuncia), el de prototipo ( $\mathrm{P}$, lo que el hablante cree que debe pronunciar) y el nivel físico (los sonidos que realmente pronuncia). Podemos ilustrar estas nociones teóricas con la pronunciación de $/ K /: \mathrm{E} / \mathrm{K} /$ esquema palatal lateral sonora, $\mathrm{PT} / \bar{K} /$ prototipo palatal lateral sonora y $[K]$ : sonido alveopalatal lateral. 
Asociadas al esquema, y también al prototipo, están las diversas variantes fonéticas conectadas en la percepción del hablante: $[K]$ alveopalatal lateral, [j] palatal fricativa, [j] aproximante palatal y [3]-[d] sonidos rehilados sonoros. Estas manifestaciones fonéticas, variantes facultativas, entidades perceptibles y reconocibles en el análisis fónico como veremos después, pueden asociarse con determinados factores sociolingüísticos y estilísticos, aunque en este caso se trata de variación no funcional (Caravedo 2014: 27) puesto que no produce cambio de significado en la mayoría de los casos.

Finalizamos este marco epistemológico con la propuesta de Martín Butragueño (2002: 167-181), quien desarrolla una teoría multidimensional del cambio fonológico estableciendo una serie de premisas; las más relevantes y que nosotros hemos aplicado en esta investigación son: la teoría del cambio fonológico debe respetar los requisitos formales de la teoría fonológica general, pero asumiendo que algunos aspectos de los cambios son universales y otros son particulares de las lenguas; cuando hay más de una causa en un proceso de variación y cambio es necesario jerarquizarlas; un cambio lo es cuando se difunde socialmente y todo cambio fónico tiene una dimensión social; por último, la jerarquía de factores que explican el proceso de cambio sigue este orden: causas sociolingüísticas $>$ acción del contexto fónico $>$ equilibrio del sistema $>$ restricciones de marcación.

\section{ASPECTOS METODOLÓGICOS}

Como ya se ha señalado, el objetivo es descubrir y cuantificar los alófonos del fonema $/ K /$ realizados por los hablantes de esta comunidad para comprender el alcance del proceso de variación y cambio fonológico. Dado que el área geográfica de referencia es una comunidad de habla bilingüe castellanocatalán, donde se usan indistintamente el castellano y la variedad dialectal del catalán conocida como valenciano, es requisito previo señalar las características fónicas del dialecto catalán que puedan incidir en el español hablado de este territorio.

$\mathrm{Al}$ estudiar las causas internas y externas de la variación fónica de este fonema en catalán, Lloret (2002: 332-336) señala que la pronunciación lateral alveopalatal $[K]$ no ha experimentado cambios en aquellas palabras procedentes de L- y -LL- intervocálica, pero que la articulación de los grupos latinos -ly-, -c'l- y -g'l- presentó cuatro resoluciones diferentes en 
el dominio lingüístico del catalán: $1 .\left(\mathrm{j} \sim{ }^{\mathrm{j})} K>\mathrm{j}\right.$ ) zona yeísta, vigente en la actualidad: Baleares, Vic...; $2 .(\mathrm{j} \sim \Lambda)$ antigua zona yeísta pero actual zona lleísta por prestigio de Barcelona: Terrassa, Sabadell, Manresa...; 3. (j $\sim K$ $>K)$ antigua zona con variación yeísta $\sim$ yeísta social $>$ actual zona lleísta: Barcelona; 4. $\left(K \sim^{(\mathrm{j})} K>\Lambda\right)$ zona lleísta hasta la actualidad: Valencia, Lérida... Por otra parte, Jiménez y Lloret (2015) señalan que en esta situación de contacto lingüístico mientras el castellano tiende a reducir la complejidad del entorno vocálico (en favor de las restricciones de marcación) y aumenta la variación superficial (contraria a las restricciones de fidelidad), en catalán las restricciones de fidelidad input-output limitan las posibilidades de adaptación del fonema $K /$.

Así pues, en la comunidad de habla marco de nuestra investigación se mantiene la pronunciación de la lateral alveopaltal $[K]$ diferenciándola de la fricativa palatal [j] y la aproximante [j]; no obstante, ya se observa en la generación de los jóvenes bilingües valencianos cierta influencia del yeísmo que pronuncian los castellanohablantes. Esta percepción se correspondería con la opinión de Lloret (2002: 333): "Si les causes del canvi són externes, una forma $\mathrm{A}$ pròpia d'una comunitat $\mathrm{X}$ passa a alternar amb una forma $\mathrm{B}$ pròpia d'una comunitat $Y$ en contacte" ", hecho relacionado con la hipótesis de convergencia lingüística entre ambas lenguas promovida por el castellano.

En otro orden de cosas, tampoco conviene olvidar el crecimiento demográfico que esta área urbana ha experimentado de forma constante desde la década de 1960 con la llegada masiva de inmigrantes de otras zonas de España y del extranjero, sobre todo en las comarcas de L'Horta (Huerta de Valencia). Según el último censo (INE 2014), Valencia ciudad cuenta con 787.301 habitantes y los cuarenta y cinco municipios de la Huerta que conforman el área metropolitana con 754.932, lo que supone una población total de 1.542 .233 personas. Esta comunidad de habla presenta un bilingüismo social intenso, extenso y estable, donde el $49.4 \%$ de sus miembros son bilingües activos y el $50.6 \%$ castellanohablantes, en su mayoría bilingües pasivos; es decir, entienden el valenciano aunque no lo usen ${ }^{12}$. Además, existe una gran permeabilidad social que ha favorecido todo tipo de transferencias.

Una vez presentado el contexto lingüístico y social de esta comunidad de habla, exponemos la metodología sobre la que se sustenta esta investigación.

\footnotetext{
11 "Si las causas del cambio son externas, una forma propia A de una comunidad X pasa a alternar con una forma B propia de una comunidad Y en contacto".

12 Fuente Generalitat Valenciana (2010): Encuesta sobre el uso y conocimiento del valenciano.
} 
Para el estudio de los sonidos se han considerado dos aplicaciones: fonética acústica y fonética perceptiva; con la primera se ha realizado el estudio acústico de los sonidos del corpus PRESEVAL ${ }^{13}$ y la segunda porque, tal como sostiene Caravedo (2014: 9) desde un enfoque sociocognitivo, la percepción desempeña un papel central en la configuración de los fenómenos lingüísticos.

En primer lugar se ha efectuado el estudio de la variable dependiente (fonema $/ K /$ ) y se han establecido dos variantes: lateral alveopalatal $([K])$ y yeísta (variante que agrupa los alófonos palatal fricativa [j] y aproximante palatal [i] ${ }^{14}$, puesto que el segundo alófono presenta muy pocos casos). Para visualizar los parámetros fónicos en las realizaciones del fonema $/ K /$ hemos aplicado el programa Praat (http:/www.fon.hum.uva.nl/praat), si bien en la mayoría de los segmentos nos hemos guiado por nuestro oído una vez corroborada la homogeneidad de criterio con el espectrograma; en los casos dudosos se ha acudido al análisis fonético acústico. Por otra parte, no se han escuchado las entrevistas semidirigidas completas sino que se han seleccionado tres fragmentos de cada conversación: ocho iniciales, ocho del intermedio y ocho finales. Es evidente que la frecuencia de uso de la variable objeto de estudio difiere según informantes, pero los 2094 casos analizados permite realizar un estudio cuantitativo significativo.

Las muestras de habla analizadas proceden de las entrevistas semidirigidas (registro neutro o semiformal) realizadas con 72 informantes seleccionados mediante un muestreo por cuotas de asignación uniforme para las variables: sexo (36 hombre, 36 mujeres), edad (20-34 años, 24 / 35-55 años, 24 / mayor de 55 años, 24), nivel sociocultural (bajo, 24 / medio, 24 / alto, 24) y lengua habitual (castellanohablantes, 36 / bilingües activos, 36). Por su parte, las variables: residencia (Valencia, 34 / Huerta Norte, 16 / Huerta Oeste 14 / Huerta Sur 8) y modo de vida (familia, 30 / ocio, 30 / trabajo, 12), además de su carácter experimental, son consecuencia de la asignación sociolingüística anterior. Las audiciones de estos fragmentos nos han mostrado tres categorías

13 (www.uv.es/preseval). Este corpus es fruto de unas 55 horas de grabación y contiene aproximadamente medio millón de palabras; el material obtenido comprende diferentes secuencias textuales (narrativas, descriptivas, expositivas, argumentativas y dialogales) y fue recopilado entre 1997 y 2005 según los procedimientos metodológicos establecidos en el PRESEEA.

14 Martínez Celdrán y Fernández Planas (2007: 169) consideran que el AFI presenta una insuficiencia en el tratamiento de las aproximantes [j] y [j], tal como se observa en la fonética del español. Según el AFI ambos segmentos son consonantes aproximantes palatales sonoras $y$, como señalan los autores, se trata de dos segmentos diferentes: [j] consonante aproximante palatal, [j] semivocal aproximante palatal. 
de hablantes: unos son distinguidores y articulan de forma diferente ambos segmentos fónicos, otros evidencian un yeísmo elevado y un tercer grupo que en ocasiones son yeístas y en otras, distinguidores.

En el ámbito de la fonética perceptiva hemos realizado recientemente un cuestionario dirigido para conocer las percepciones de los hablantes y comprobar el grado de discriminación acústica de ambos fonemas. Asumimos que la percepción del hablante es una percepción subjetiva, parcial, limitada por las realizaciones fonéticas de su comunidad de habla, pero es un mecanismo fundamental en la explicación de la variación lingüística. Consideramos relevante averiguar cómo empezó a propagarse esa innovación yeísta en nuestra comunidad de habla; este interés coincide con la opinión de Labov (2001: 29): «The strategy to be followed here is to transform the traditional question "Why does language change?" into a different form: "Who are the leaders of linguistic change?"》 (La estrategia que debe seguirse en este caso es transformar la pregunta tradicional ¿Por qué cambia la lengua? por esta otra ¿Quiénes lideran el cambio lingüístico?).

Para ello se han diseñado y realizado dos pruebas con carácter experimental: una, general, para veinticuatro jueces estratificados como sigue: doce hombres y doce mujeres, ocho hablantes de cada generación (20-34 años/35-55 años/más de 55 años), doce bilingües y doce castellanohablantes, doce residentes en la ciudad y doce en los pueblos de área metropolitana; y otra, específica, dado el incremento que se observa en la generación joven, para cuarenta jueces estudiantes de Grado y de Máster de nuestra universidad. La estratificación de la muestra de jóvenes universitarios (20-34 años) queda distribuida así: sexo, 20 hombres/20 mujeres; lengua habitual, 20 castellanohablantes / 20 bilingües; residencia, 19 ciudad de Valencia/21 pueblos del área metropolitana.

Los estímulos, emitidos por un hablante bilingüe distinguidor de ambos fonemas, han consistido en ofrecer diez frases contextualizadas donde aparecen dichos fonemas en idénticos entornos vocálicos -VCV-. Previamente se ha advertido a todos los jueces que no tengan en cuenta la ortografía de la palabra pues los sonidos pueden estar modificados. Las frases son: "se calló porque cayó al suelo", "esa maya no es de tu taya" (malla, talla), "vaya valla", "hasta el cuarenta de mallo no te quites el sallo (mayo, sayo), "esa pulla es tuya", "esa playa no está llana", "ese anillo es una maravilla", "el caballo es bayo", "el pollo está junto al poyo", "el barullo me aturrulla". Los jueces, tras escuchar el estímulo dos veces, señalan si perciben sonidos diferentes, sonidos iguales $[K]$ o sonidos iguales [j]. En el apartado siguiente ofrecemos los resultados y su correspondiente análisis cualitativo. Como señala Ohala (2012) el motivo central de las alteraciones en el sistema fonológico hay que buscarlas en el oyente, que es quien percibe el input y tras procesarlo, lo interpreta según las restricciones propias de su sistema. 
A continuación pasamos a presentar las variables dependiente e independientes que se han determinado a fin de que nos permitan establecer el contexto de variación estable o de cambio lingüístico. Como señala Martín Butragueño (2002: 114) "lo que ofrece la sociolingüística variacionista es un método privilegiado por la riqueza de los datos y por la explicitud cualitativa y cuantitativa con que se formulan las generalizaciones sobre los mismos".

La variable dependiente es la consonante palatal lateral $/ K / \mathrm{y}$ sus posibles realizaciones fonéticas. Como ya se ha señalado, el sistema de transcripción empleado para estudiar la posible deslateralización y desarrollo de la variante yeísta es el del AFI. La codificación para su análisis es:

0 . lateral palatal o lateral alveopalatal: $[\kappa]$

1. variantes yeístas (conjunto de realizaciones no laterales que suponen una relajación de la tensión en los órganos articulatorios): [j] fricativa palatal $+[\mathrm{j}]$ aproximante palatal.

En cuanto a las variables independientes se han considerado todos los factores internos (lingüísticos) y externos (estilísticos y sociales) que, a nuestro juicio, pudieran mostrar alguna explicación en el dinamismo de este fenómeno.

De carácter lingüístico se han establecido las siguientes variables:

a) Posición del segmento. La tradición lingüística muestra cómo la variación posicional puede alterar la producción fónica. Se han codificado cuatro posiciones: 0 . posición interior de palabra (paella, bachiller) / 1 . fonética sintáctica, sinalefa (la llave, quiero llenar) / 2. posición inicial de palabra (sin vocal anterior o tras silencio) (llover) / 3. posición final de palabra (Sabadell, Carbonell)

b) Tonicidad de la sílaba donde aparece el segmento: 0. sílaba tónica / 1.sílaba pretónica / 2.sílaba postónica

c) Estructura acentual de la palabra: 0. aguda / 1. llana / 2. esdrújula o sobreesdrújula

d) Para averiguar qué entornos vocálicos favorecen la desfonologización de $/ K /$, se han analizado todas las posibles combinaciones:

/a-a/ falla, toalla, /a-e/ calle, taller, /a-o/ caballo, callo, /a-i/ allí, gallina, /e-a/ paella, botella, estrella, /e-o/ ellos, aquello,

/o-a/ olla, /o-o/ pollo,

/i-a/ maravilla, tortilla, /i-e/ bachillerato, rosquilleta, /i-o/ millones, amarillo, /u-a/ patrulla, /u-o/ capullo, /otros/ (lloraba sin cesar) 
La codificación ha sido:

d.1) entorno vocálico anterior: 0 , a / 1, e / 2, i / 3, o / 4, u / 9, otros

d.2) entorno vocálico posterior: $0, \mathrm{a} / \mathrm{1}, \mathrm{e} / 2, \mathrm{i} / 3, \mathrm{o} / 4$, u / 9, otros

e) Categoría gramatical de la palabra: 0 , verbo-participio / 1 , sustantivo / 2 , adjetivo / 3, pronombre / 4, adverbio / 5, determinante-modificador / 9 , otros

Por su parte, y aunque el corpus se cataloga como registro neutro o semiformal, las variables de carácter estilístico establecidas intentan verificar y cuantificar si ejercen alguna influencia sobre la articulación del fonema motivada por el contexto comunicativo. Son:

f) Tenor - estatus. Información correspondiente a la relación de estatus social entre el informante (I) y el entrevistador (E).: 0. iguales (igualdad de estatus, prestigio) / 1. Jerarquía $\mathrm{I}<\mathrm{E}$ (el informante muestra un estatus inferior respecto del entrevistador) / 2. Jerarquía $\mathrm{I}>\mathrm{E}$ (el informante muestra un estatus superior respecto del entrevistador).

g) Tenor - edad. La forma de tratamiento manifestada al inicio de la entrevista semidirigida puede influir en el grado de atención prestado al habla por el informante: 0 . iguales (hablante y entrevistador tienen, aproximadamente, la misma edad) $/ 1 . \mathrm{I}<\mathrm{E}$ (el informante es más joven que el entrevistador) / 2. I $>\mathrm{E}$ (el informante es mayor que el entrevistador).

h) Tenor - proximidad. La relación entre entrevistador y entrevistado varía en las muestras de habla obtenidas y con ello la tensión comunicativa o grado de espontaneidad. Los lazos contemplados en nuestro estudio en relación con la red social son: 0 . insider. Representa una relación estrecha entre el entrevistador y el informante (amistad, parientes, compañeros o vecinos de la red personal de contactos) / 1. outsider. Hablante y entrevistador presentan vínculos débiles de contacto / 2. cuando la relación ha surgido en la propia entrevista.

i) Campo. Se refiere al grado de especialización del tema objeto de conversación; los valores contemplados son dos: 0. no técnico (temas generales: asuntos cotidianos, la familia, ocio...) / 1. técnico (contexto temático específico: drogadicción, fomento del empleo...).

j) Tipo de texto. Las entrevistas que constituyen el corpus de este estudio combinan una serie de propósitos comunicativos que se corresponden con diferentes secuencias textuales (Calsamiglia y Tusón 1999: 319). Los tipos de texto delimitados son: 0 . diálogo / 1. explicativo-expositivo / 2. narrativo / 3. argumentativo / 4. descriptivo. 
k) Fase de la entrevista. Con objeto de poder distinguir fases de mayor espontaneidad en el conjunto de la entrevista semidirigida se han escogido fragmentos que corresponden a tres etapas en su desarrollo y con una duración aproximada de ocho minutos cada uno: 0 . comienzo (se trata de fragmentos narrativos y expositivos por lo general) / 1. intermedio (surgen textos expositivos, argumentativos y descriptivos) / 2. final (aparecen textos mayoritariamente dialogales, más propios de un registro coloquial: viajes, lotería...).

Finalmente, se han delimitado como variables sociales las consideradas de mayor incidencia en otros estudios similares.

1) Sexo o género: 0 , hombre / 1 , mujer. Dada la consideración sociolingüística de prestigio abierto en la producción yeísta, esta variable puede ser relevante.

m) Edad. Tres estratos generacionales: 0, joven (20-34 años) / 1, adulto $>$ (35-55 años) $/ 2$, mayor de 55 años. Otra de las hipótesis planteadas es el peso determinante de la edad en el proceso de deslateralización. Es evidente que el cambio se produce por saltos generacionales más o menos abruptos, por reanálisis en las gramáticas de los nuevos hablantes, pero en el proceso de cambio intervienen otros muchos factores.

n) Nivel sociocultural. Esta variable postestratificacional aglutina el nivel de estudios y la profesión; no obstante, predomina el grado de instrucción: 0 , sociolecto bajo / 1 , sociolecto medio / 3 , sociolecto alto.

o) Lengua habitual. Aunque también se obtiene información en la encuesta sobre la lengua materna de los informantes, se ha considerado más útil el uso comunicativo cotidiano; así, la adscripción lingüística es: 0 , castellanohablantes y bilingües pasivos / 1 , bilingües activos. Como observadores participantes hemos comprobado que la interacción oral es distinta: mientras en la ciudad predomina el castellano, en las comarcas de la Huerta se usa más el valenciano.

p) Consecuencia de la observación anterior es el diseño de la variable residencia, no solo por el uso mayoritario distinto de ambas modalidades lingüísticas sino también porque las redes sociales son más estrechas en los pueblos y más difusas en la ciudad. Las variantes son: 0 , ciudad / 1, Huerta Norte (zona eminentemente agrícola, menor inmigración) / 2, Huerta Oeste (zona con mucha industria, fuerte inmigración de otros territorios nacionales) / 3, Huerta Sur (combina agricultura e industria, menor inmigración). Posteriormente y para establecer el carácter urbano/ rural del yeísmo, se han delimitado solo dos variantes de ubicación: 0 , Valencia ciudad / 1, pueblos. 
q) Modo de vida. Complementando el valor que puedan manifestar o determinar las redes sociales, esta variable responde a la consideración de grupos sociales internamente estructurados y relacionados con otros grupos. Se han establecido tres posibilidades:

0 . Familia, redes sociales densas y múltiples, relaciones cooperativas (agricultor, limpiadora, cajera de supermercado, ama de casa, operario de almacén, panadero, peluquera, cocinero, frutera, vendedor ambulante...) 1. Ocio, ganar un sueldo y disponer de tiempo libre, trabajo separado del ámbito familiar (oficinista, profesora EGB, funcionario, profesor Secundaria, traductora, técnico Obras Públicas, técnico lingüístico...)

2. Trabajo, planifica y dirige trabajos de otras personas, existe actitud competitiva (director de banco, profesor de universidad, político, abogado, empresario, jefe de recursos humanos, secretaria alta dirección, editora...).

Finalmente, asumiendo que puede tratarse de un fenómeno de causación múltiple, es requisito imprescindible jerarquizar la incidencia de los factores internos y externos que intervienen en el proceso; para ello se han realizado cálculos de estadística descriptiva y de estadística inferencial La estadística descriptiva permite conocer la distribución de los datos de las variables independientes en relación con la variable dependiente; a este tipo de análisis pertenece el cálculo de frecuencias absolutas y relativas, la ordenación o clasificación de los resultados, $\mathrm{Chi}^{2}$, la significación estadística ${ }^{15}$ y las correlaciones entre variables independientes. Por su parte, la estadística inferencial permite proyectar las características de la muestra sobre la población objeto de estudio, es decir, permite hacer inferencias de grandes grupos a partir de la información proporcionada por pequeños grupos; para ello realiza análisis multivariables mediante paquetes estadísticos y programas informáticos. En el presente trabajo, para la cuantificación y análisis de la regla variable se han aplicado dos programas, SPSS para Windows16 y Goldvarb 2001: A Multivariate analysis applications for

15 El Chi cuadrado $\left(\chi^{2)}\right.$ se construye a partir de las diferencias entre las frecuencias observadas y las esperadas bajo la hipótesis de independencia y prueba si existe o no asociación entre las variables. Se considera que la variable presenta significación estadística cuando el valor $p$ es igual o menor a 0.05 ; en este caso, se refuta la hipótesis de independencia, es decir, que existe cierta relación asociativa entre las variables y los resultados obtenidos no dependen del azar o de causas aleatorias.

16 El paquete SPSS es un sistema amplio y flexible de análisis estadístico y gestión de datos. La versión aquí utilizada es la 22. Esta herramienta aporta numerosas opciones de estadística descriptiva, estadística bivariable, estadística predictiva con variables dependientes 
Windows ${ }^{17}$, y así poder comparar sus ventajas e inconvenientes. Tras los resultados obtenidos evaluaremos cuál de ellos muestra mayor utilidad en la investigación sociolingüística.

\section{ANÁLISIS CUANTITATIVO Y CUALITATIVO}

Dado que todas las variables objeto de análisis pueden catalogarse como nominales (Hernández y Almeida 2005: 202) y presentan una frecuencia de variantes suficiente para el estudio cuantitativo, se han codificado y tabulado los datos para su análisis. La distribución general de las realizaciones fonéticas de $/ \mathrm{K} /$ en nuestra comunidad de habla bilingüe suman 2094 casos: palatal lateral $[K] 1590$ veces $(75.9 \%)$ y realizaciones no laterales $[j]+[j] 504$ casos $(24.1 \%)^{18}$. Asimismo, hemos encontrado hablantes de tres categorías: distinguidores $(41.7 \%)$, distinguidores que también producen algunas secuencias yeístas (33.3\%) y otros sustancialmente yeístas $(25.0 \%)$.

continuas o cuantitativas (regresión lineal) y estadística predictiva para la identificación de grupos (entre otros, análisis factorial, análisis de clusters y análisis discriminante). Para ampliar información, véase Visauta (2001).

17 El programa GoldVarb 2001 (http://www.york.ac.uk) en su última versión (Goldvarb $X)$ permite averiguar cuál es la probabilidad de que se seleccione una de las dos variantes de la variable dependiente cuando actúan de forma combinada todas las variables independientes; en este caso se ha seleccionado la aproximante lateral. Además de seleccionar las variables que inciden de forma significativa en la variable dependiente, indica el peso probabilístico o grado de incidencia de cada una de las variantes (si la probabilidad es superior a 0.5 , se considera que esa variante favorece la pluralización, mientras que si es inferior, favorece el uso del singular; y si el valor está próximo a 0.5 no ejerce influencia sustancial en uno u otro caso. Para mayor ampliación, véase Robinson, Lawrence y Tagliamore (2001) y Paolillo (2001).

18 Si comparamos estos datos con trabajos recientes de nuestro entorno, comprobamos que Moratal (2011) investiga el yeísmo entre los hablantes monolingües y bilingües de todos los sociolectos de la ciudad valenciana de Gandía y obtiene una realización $[K]$ del $64.3 \%$ y una realización yeísta del 35.7\%. Por su parte, Molina Martos (2013) investiga el yeísmo madrileño en los ámbitos campo/ciudad; para los pueblos madrileños señala una realización $[\Lambda]$ del $7.0 \%$ y una realización no lateral $[j+I+j+3]$ del $93.0 \%$, mientras que para el área urbana de Madrid obtiene una realización $[\Lambda]$ del $0.0 \%$ y una distribución de las otras variantes como sigue: [j] $95.0 \%$, [I] $3.0 \%$ y [j] $2.0 \%$. 


\subsection{REALIZACIÓN DEL FONEMA / $/ /$}

A continuación se muestran de forma detallada las frecuencias absolutas y relativas al relacionar la variable dependiente con cada una de las variables independientes; es el producto de un análisis cuantitativo bivariante realizado con SPSS; este análisis incluye, además de las frecuencias, la significación estadística de los resultados obtenidos para poder refutar o no la hipótesis nula ${ }^{19}$.

Tabla 1. Resultados del análisis de la contingencia entre la variable dependiente y las variables independientes. Frecuencias y significación estadística

\begin{tabular}{|c|c|c|c|c|c|c|c|c|}
\hline Variable y variantes & lateral & $\%$ & no lateral & $\%$ & Total & $\chi^{2}(\mathrm{gl})$ & \begin{tabular}{|c|} 
V de \\
Cramer
\end{tabular} & $\mathrm{p}$ \\
\hline $\begin{array}{l}\text { (1) posición } \\
\text { del segmento } \\
\text { - interior palabra } \\
\text { - sinalefa } \\
\text { - inicial } \\
\text { - final }\end{array}$ & $\begin{array}{c}1251 \\
244 \\
87 \\
8\end{array}$ & $\begin{array}{l}75.3 \\
79.0 \\
75.6 \\
88.9\end{array}$ & $\begin{array}{c}410 \\
65 \\
28 \\
1\end{array}$ & $\begin{array}{l}24.7 \\
21.0 \\
24.4 \\
11.1\end{array}$ & $\begin{array}{c}1661 \\
309 \\
115 \\
9\end{array}$ & 2,731 & 0.036 & 0.435 \\
\hline $\begin{array}{l}\text { (2) tonicidad } \\
\text { - sílaba tónica } \\
\text { - sílaba pretónica } \\
\text { - sílaba postónica }\end{array}$ & $\begin{array}{l}586 \\
504 \\
500\end{array}$ & $\begin{array}{l}77.2 \\
80.4 \\
70.6\end{array}$ & $\begin{array}{l}173 \\
123 \\
208\end{array}$ & $\begin{array}{l}22.8 \\
19.6 \\
29.4\end{array}$ & $\begin{array}{l}759 \\
627 \\
708\end{array}$ & $\begin{array}{c}18,396 \\
(2)\end{array}$ & 0.094 & 0.000 \\
\hline $\begin{array}{l}\text { (3) estructura acentual } \\
\text { - aguda } \\
\text { - llana } \\
\text { - esdrújula }\end{array}$ & $\begin{array}{c}401 \\
1159 \\
30\end{array}$ & $\begin{array}{l}80.5 \\
74.1 \\
96.8\end{array}$ & $\begin{array}{c}97 \\
406 \\
1\end{array}$ & $\begin{array}{c}19.5 \\
25.9 \\
3.2\end{array}$ & $\begin{array}{c}498 \\
1565 \\
31\end{array}$ & $\begin{array}{c}16,118 \\
(2)\end{array}$ & 0.088 & 0.000 \\
\hline $\begin{array}{l}\text { (4) vocal anterior } \\
-\mathrm{a} \\
-\mathrm{e} \\
-\mathrm{i} \\
-\mathrm{o} \\
-\mathrm{u} \\
- \text { otros }\end{array}$ & $\begin{array}{c}514 \\
554 \\
295 \\
126 \\
12 \\
89\end{array}$ & $\begin{array}{l}78.8 \\
80.8 \\
63.7 \\
77.3 \\
80.0 \\
76.7\end{array}$ & $\begin{array}{c}138 \\
131 \\
168 \\
37 \\
3 \\
27\end{array}$ & $\begin{array}{l}21.2 \\
19.2 \\
36.3 \\
22.7 \\
20.0 \\
23.3\end{array}$ & $\begin{array}{c}652 \\
685 \\
463 \\
163 \\
15 \\
116\end{array}$ & $\begin{array}{c}50,322 \\
(5)\end{array}$ & 0.155 & 0.000 \\
\hline
\end{tabular}

19 Esta hipótesis supone que los resultados obtenidos dependen del azar o de causas aleatorias; es decir, que no son significativos estadísticamente. El valor $\mathrm{p}$ asignado para rechazar la hipótesis nula es $0,05(\mathrm{p}<0.05)$. Por su parte, la $V$ de Cramer mide el grado de asociación y toma valores entre 0 y 1 (los valores próximos a 0 indican no asociación entre las variables y los valores próximos a 1 , fuerte asociación). 


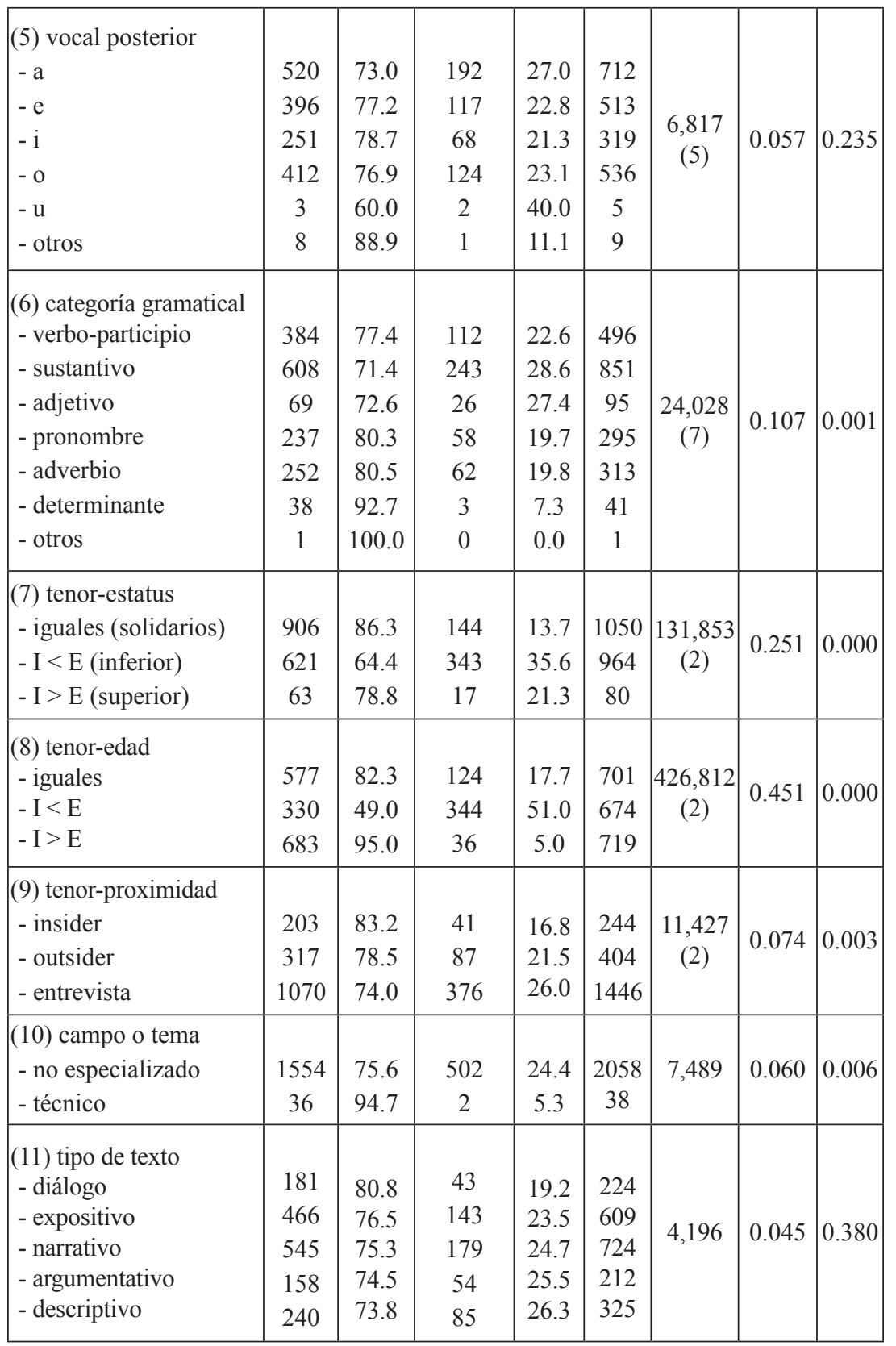




\begin{tabular}{|c|c|c|c|c|c|c|c|c|}
\hline $\begin{array}{l}\text { (12) fase de la entrevista } \\
\text { - inicio } \\
\text { - intermedio } \\
\text { - final }\end{array}$ & $\begin{array}{l}572 \\
551 \\
467\end{array}$ & $\begin{array}{l}76.6 \\
76.1 \\
65.0\end{array}$ & $\begin{array}{l}175 \\
173 \\
156\end{array}$ & $\begin{array}{l}23.4 \\
23.9 \\
25.0\end{array}$ & $\begin{array}{l}747 \\
724 \\
623\end{array}$ & $\begin{array}{c}0,502 \\
(2)\end{array}$ & 0.015 & 0.778 \\
\hline $\begin{array}{l}\text { (13) sexo } \\
\text { - masculino } \\
\text { - femenino }\end{array}$ & $\begin{array}{l}943 \\
647\end{array}$ & $\begin{array}{l}87.4 \\
63.7\end{array}$ & $\begin{array}{l}136 \\
368\end{array}$ & $\begin{array}{l}12.6 \\
36.3\end{array}$ & $\begin{array}{l}1079 \\
1015\end{array}$ & $\begin{array}{c}160,092 \\
\text { (1) }\end{array}$ & 0.277 & 0.000 \\
\hline $\begin{array}{l}\text { (14) edad } \\
-20-34 \text { años } \\
\text { - 35-55 años } \\
\text { - mayor de } 55 \text { años } \\
\end{array}$ & $\begin{array}{l}318 \\
597 \\
675\end{array}$ & $\begin{array}{l}47.0 \\
83.0 \\
96.5\end{array}$ & $\begin{array}{c}358 \\
122 \\
24\end{array}$ & $\begin{array}{c}53.0 \\
17.0 \\
3.5\end{array}$ & $\begin{array}{l}676 \\
719 \\
699\end{array}$ & 491,418 & 0.484 & 0.000 \\
\hline $\begin{array}{l}\text { (15) nivel sociocultural } \\
\text { - bajo } \\
\text { - medio } \\
\text { - alto }\end{array}$ & $\begin{array}{l}538 \\
572 \\
480\end{array}$ & $\begin{array}{l}73.4 \\
76.1 \\
78.8\end{array}$ & $\begin{array}{l}195 \\
180 \\
129\end{array}$ & $\begin{array}{l}26.6 \\
23.9 \\
21.2\end{array}$ & $\begin{array}{l}733 \\
752 \\
609\end{array}$ & $\begin{array}{c}5,360 \\
(2)\end{array}$ & 0.051 & 0.059 \\
\hline $\begin{array}{l}\text { (16) lengua habitual } \\
\text { - bilingüe } \\
\text { - castellano- hablante }\end{array}$ & $\begin{array}{l}856 \\
734\end{array}$ & $\begin{array}{l}80.1 \\
71.6\end{array}$ & $\begin{array}{l}213 \\
291\end{array}$ & $\begin{array}{l}19.9 \\
28.4\end{array}$ & $\begin{array}{l}1069 \\
1025\end{array}$ & $\begin{array}{c}20,517 \\
\text { (1) }\end{array}$ & 0.099 & 0.000 \\
\hline $\begin{array}{l}\text { (17) residencia } \\
\text { - Valencia ciudad } \\
\text { - pueblos Huerta N. } \\
\text { - pueblos Huerta O } \\
\text { - pueblos Huerta S }\end{array}$ & $\begin{array}{l}744 \\
432 \\
233 \\
181\end{array}$ & $\begin{array}{l}74.3 \\
82.0 \\
65.6 \\
86.2\end{array}$ & $\begin{array}{c}258 \\
95 \\
122 \\
29\end{array}$ & $\begin{array}{l}25.7 \\
18.0 \\
34.4 \\
13.8\end{array}$ & $\begin{array}{c}1002 \\
527 \\
355 \\
210\end{array}$ & $\begin{array}{c}44,766 \\
(3)\end{array}$ & 0.146 & 0.000 \\
\hline $\begin{array}{l}\text { (18) ubicación } \\
\text { - ciudad } \\
\text { - pueblos }\end{array}$ & $\begin{array}{l}744 \\
846\end{array}$ & $\begin{array}{l}74.3 \\
77.5\end{array}$ & $\begin{array}{l}258 \\
246\end{array}$ & $\begin{array}{l}25.7 \\
22.5\end{array}$ & $\begin{array}{l}1002 \\
1092\end{array}$ & $\begin{array}{c}2,966 \\
(1)\end{array}$ & 0.038 & 0.085 \\
\hline $\begin{array}{l}\text { (19) modo de vida } \\
\text { - familia } \\
\text { - ocio } \\
\text { - trabajo }\end{array}$ & $\begin{array}{l}729 \\
603 \\
258\end{array}$ & $\begin{array}{l}78.7 \\
71.2 \\
80.4\end{array}$ & $\begin{array}{c}197 \\
244 \\
63\end{array}$ & $\begin{array}{l}21.3 \\
28.8 \\
19.6\end{array}$ & $\begin{array}{l}926 \\
847 \\
321\end{array}$ & $\begin{array}{c}17,831 \\
(2)\end{array}$ & 0.092 & 0.000 \\
\hline
\end{tabular}

Los resultados anteriores nos permiten destacar algunos aspectos relevantes:

- El conjunto de realizaciones intervocálicas, sea interior de palabra o sinalefa, supone 1970 casos; es decir, el 94.1\% del total. Es escasa la frecuencia al inicio de palabra $(5.5 \%)$ y muy reducida su presencia en posición final $(0.4 \%)$. 
- Hay seis grupos de factores que no ofrecen significación estadística, cuatro de ellos con un valor sustancial: dos estilísticos -fase de la entrevista $(p=0.778)$ y tipo de texto $(p=0.380)-y$ dos lingüísticos -posición del segmento $(\mathrm{p}=0.435)$ y vocal posterior $(\mathrm{p}=0.235)$-; por su parte, dos variables sociales muestran valores cercanos al mínimo establecido -ubicación $(\mathrm{p}=0.085)$ y nivel sociocultural del hablante $(\mathrm{p}=0.059)$ -

- Los valores $V$ de Cramer nos indican una primera incidencia jerarquizada de algunas variables independientes sobre la dependiente; son: edad (0.484), tenor-edad (0.451), sexo (0.277), tenor-estatus $(0.251)$, vocal anterior $(0.155)$ y residencia $(0.146)$.

- Los entornos vocálicos con mayor frecuencia son: aCe (calle, ya llega) / aCi (allí) / aCa (fallas, la llave) / aCo (caballo) eCa (paella) / eCo (aquello) / eCe (relleno, se lleva) iCo (castillo) / iCa (chiquilla) / iCe (bachillerato) oCa (olla) / oCo (pollo) / oCe (mollejas)

Y con menor frecuencia: \#Cv (Llegado el momento... / Llovía cuando...) uCa (patrulla) / uCi (tullido) / uCo (barullo)

- Las variables 'estratificación generacional', 'sexo' y 'adscripción lingüística' presentan resultados similares, aunque en diferente proporción, con los obtenidos en la ciudad de Barcelona (Torres et al. 2011) y en otras comarcas de la Comunitat Valenciana (Segura 2003, Moratal 2011): el yeísmo está más avanzado en el estrato generacional joven, en las mujeres y en los castellanohablantes; asimismo, el porcentaje de distinguidores es mayor en los hablantes bilingües $(60.0 \%)$.

- Por último, como apunta Martín Butragueño (2012: 22), es muy productivo descubrir quiénes actúan como líderes del proceso de desfonologización; para ello hemos agrupado los datos relativos a la edad y al sexo de forma combinada en nuestra investigación mediante una tabulación cruzada: $\chi^{2}=27.748, \mathrm{gl}$ (2) y significación estadística 0.000), y observamos que los líderes de este proceso en nuestra comunidad de habla son las mujeres jóvenes seguida por los varones de esa misma generación; esta valoración podrá contrastarse después con el estudio de fonética perceptiva. 


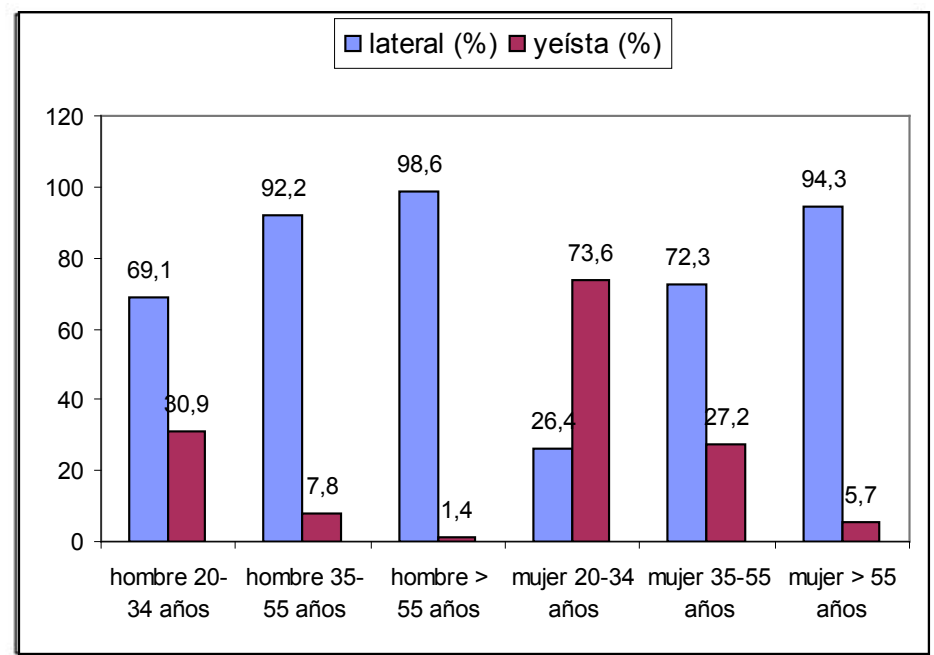

Gráfico 1. Proporción de hablantes distinguidores y yeístas según sexo y edad

\subsection{Yeísmo}

Posteriormente, se ha procedido al análisis multivariante de regresión logística mediante los programas SPSS y GOLDVARB 2001, tomando las variantes yeístas como valor de aplicación para conocer el estado del proceso de deslateralización. En nuestro caso, los resultados son prácticamente coincidentes en ambos cálculos; esta es la aportación de cada uno de ellos ${ }^{20}$ :

- el Binomial Varbrul (Goldvarb 2001) nos indica un input (índice de variablidad del fenómeno) de 0,241 , dato que coincide con el porcentaje de la frecuencia del yeísmo. Para calcular la incidencia probabilística de todas las variables independientes combinadas

20 Los dos programas comparan todos los modelos posibles de combinación de las variables o grupos de factores y seleccionan el que se ajusta mejor a los datos: determinan, en primer lugar, si existe o no relación entre una o más variables independientes y la dependiente, a continuación miden la magnitud de esa relación y, por último, estiman la probabilidad de que se produzca un hecho similar en función de los valores asignados a las variables independientes. Los pesos probabilísticos por encima de 0.500 favorecen las variantes yeístas mientras que los que se hallan por debajo, favorecen el uso de la lateral palatal; los valores de 0,500 o próximos a él no ejercen influencia sustancial en uno u otro sentido. 
respecto de la variable dependiente, realiza dos fases: set-up \& down. Los valores obtenidos en ambas fases coinciden en la selección de las variables independientes y sus variantes con mayor peso probabilístico; por otra parte, elimina de forma progresiva aquellas variables que no intervienen en la variación del fenómeno ${ }^{21}$; estas son, según orden descendente: categoría gramatical de la palabra, fase de la interacción, posición del segmento, vocal posterior, estructura acentual de la palabra y ubicación - ciudad/pueblos-;

- por su parte, el paquete informático SPSS realiza el análisis de regresión logística binomial mediante el método de pasos; en este caso, las variables seleccionadas coinciden con las establecidas por Goldvarb pero varían ligeramente según el rango ${ }^{22}$; asimismo, las variables rechazadas coinciden en su conjunto pero difieren en el orden de exclusión: categoría gramatical, estructura acentual de la palabra, fase de la interacción, posición del segmento, vocal posterior y ubicación.

A continuación presentamos una tabla resumen donde pueden comprobarse los valores asignados por cada programa estadístico a las variables independientes o grupos de factores:

Tabla 2. Resultados de los análisis de regresión logística binomial efectuados con Goldvarb y SPSS. Incidencia de las variables independientes (y sus variantes) sobre la realización yeísta: pesos y significación estadística

\begin{tabular}{|l|l|l|c|c|}
\hline \multicolumn{5}{|c|}{ Variantes yeístas [j] + [j] } \\
\hline $\begin{array}{c}\text { Variables } \\
\text { independientes }\end{array}$ & $\begin{array}{c}\text { GOLDVARB } \\
\text { Peso }\end{array}$ & $\begin{array}{c}\text { Variables } \\
\text { independientes }\end{array}$ & $\begin{array}{c}\text { SPSS } \\
\text { Peso }\end{array}$ & $\begin{array}{c}\text { Significación } \\
\text { estadística }\end{array}$ \\
\hline Edad (rango 0.600) & & Edad (rango 0.607) & & 0.000 \\
\hline - 20-34 años & 0,809 & $-20-34$ años & 0,813 & 0,000 \\
- 35-55 años & 0.473 & $-35-55$ años & 0,470 & 0,527 \\
- mayor de 55 años & 0,209 & - mayor de 55 años & 0,206 & 0,000 \\
\hline
\end{tabular}

21 El orden de eliminación indica la nula o escasa aportación de cada una de ellas a la explicación de la variable objeto de estudio.

22 El rango es una medida que se obtiene de la diferencia entre la variante de mayor y la de menor peso de cada variable; cuanto mayor sea el rango, mayor incidencia. Las variables con un rango igual o inferior a 0.200 muestran escaso valor explicativo y predictivo. 


\begin{tabular}{|c|c|c|c|c|}
\hline \multicolumn{2}{|l|}{$\begin{array}{l}\text { Campo o tema } \\
\text { (rango 0.580) }\end{array}$} & \multicolumn{2}{|l|}{$\begin{array}{l}\text { Campo o tema } \\
\text { (rango 0.582) }\end{array}$} & \multirow{3}{*}{$\begin{array}{l}0.002 \\
0,002 \\
0,002\end{array}$} \\
\hline - no especializado & 0,790 & - no especializado & 0,791 & \\
\hline - técnico & 0,210 & - técnico & 0,209 & \\
\hline \multicolumn{2}{|l|}{$\begin{array}{l}\text { Tenor-edad } \\
\text { (rango 0.530) }\end{array}$} & \multicolumn{2}{|l|}{$\begin{array}{l}\text { Tenor-edad } \\
\text { (rango 0.522) }\end{array}$} & 0.000 \\
\hline$-\mathrm{I}<\mathrm{E}$ & 0,771 & - iguales & 0,766 & 0,000 \\
\hline - iguales & 0,484 & $-\mathrm{I}<\mathrm{E}$ & 0,485 & 0,035 \\
\hline$-\mathrm{I}>\mathrm{E}$ & 0,241 & $-I>E$ & 0,244 & 0,000 \\
\hline \multicolumn{2}{|l|}{$\begin{array}{l}\text { Residencia } \\
\text { (rango 0.479) }\end{array}$} & \multicolumn{2}{|l|}{$\begin{array}{l}\text { Residencia } \\
(\text { rango 0.481) }\end{array}$} & 0.000 \\
\hline - Valencia ciudad & 0,703 & - Valencia ciudad & 0,704 & 0,000 \\
\hline - pueblos Huerta Oeste & 0,673 & - pueblos Huerta Oeste & 0,673 & 0,000 \\
\hline - pueblos Huerta Sur & 0,415 & - pueblos Huerta Sur & 0,415 & 0,080 \\
\hline - pueblos Huerta Norte & 0,224 & - pueblos Huerta Norte & 0,223 & 0,000 \\
\hline \multicolumn{2}{|l|}{$\begin{array}{l}\text { Sexo o género } \\
\text { (rango } 0.438)\end{array}$} & \multicolumn{2}{|l|}{ Sexo (rango 0.438) } & 0,0500 \\
\hline - femenino & 0,719 & - femenino & 0,719 & 0,0500 \\
\hline - masculino & 0,281 & - masculino & 0,281 & 0,0500 \\
\hline \multicolumn{2}{|l|}{$\begin{array}{l}\text { Tenor-estatus } \\
\text { (rango 0.432) }\end{array}$} & \multicolumn{2}{|l|}{$\begin{array}{l}\text { Tenor-estatus } \\
(\text { rango 0.425) }\end{array}$} & 0.000 \\
\hline$-\mathrm{I}<\mathrm{E}($ superior $)$ & 0,740 & - I $<$ E (superior) & 0,735 & 0,001 \\
\hline - iguales (solidarios) & 0,442 & - iguales (solidarios) & 0,446 & 0,205 \\
\hline$-\mathrm{I}>\mathrm{E}$ (inferior) & 0,308 & - I > E (inferior) & 0,310 & 0,000 \\
\hline \multicolumn{2}{|l|}{$\begin{array}{l}\text { Vocal anterior } \\
\text { (rango 0.339) } \\
\end{array}$} & \multicolumn{2}{|l|}{$\begin{array}{l}\text { Vocal anterior } \\
\text { (rango 0.339) } \\
\end{array}$} & 0.000 \\
\hline$-\mathrm{i}$ & 0,741 & $-\mathrm{i}$ & 0,741 & 0,000 \\
\hline$-\mathrm{u}$ & 0,567 & $-\mathrm{u}$ & 0,568 & 0,690 \\
\hline - otros & 0,453 & - otros & 0,454 & 0,527 \\
\hline$-\mathrm{e}$ & 0,409 & $-\mathrm{e}$ & 0,408 & 0,048 \\
\hline-0 & 0,408 & -0 & 0,408 & 0,132 \\
\hline$-\mathrm{a}$ & 0,402 & $-\mathrm{a}$ & 0,402 & 0,035 \\
\hline \multicolumn{2}{|l|}{$\begin{array}{l}\text { Tenor proximidad } \\
\text { (rango } 0.320)\end{array}$} & \multicolumn{2}{|l|}{$\begin{array}{l}\text { Tenor proximidad } \\
\text { (rango } 0.320)\end{array}$} & 0.000 \\
\hline - insider & 0,622 & - insider & 0,623 & 0,007 \\
\hline - outsider & 0,619 & - outsider & 0,618 & 0,003 \\
\hline - entrevista & 0,302 & - entrevista & 0,303 & 0,000 \\
\hline \multicolumn{2}{|l|}{$\begin{array}{l}\text { Nivel socio cultural } \\
\text { (rango } 0.248 \text { ) }\end{array}$} & \multicolumn{2}{|l|}{$\begin{array}{l}\text { Nivel socio cultural } \\
\text { (rango } 0.251 \text { ) }\end{array}$} & 0.000 \\
\hline
\end{tabular}




\begin{tabular}{|c|c|c|c|c|}
\hline $\begin{array}{l}\text { - bajo } \\
\text { - medio } \\
\text { - alto }\end{array}$ & $\begin{array}{l}0,648 \\
0,449 \\
0,400\end{array}$ & $\begin{array}{l}\text { - bajo } \\
\text { - medio } \\
\text { - alto }\end{array}$ & $\begin{array}{l}0,649 \\
0,450 \\
0,398\end{array}$ & $\begin{array}{l}0,011 \\
0,107 \\
0,000\end{array}$ \\
\hline \multicolumn{2}{|l|}{$\begin{array}{l}\text { Lengua habitual } \\
\text { (rango 0.218) }\end{array}$} & \multicolumn{2}{|l|}{$\begin{array}{l}\text { Lengua habitual } \\
\text { (rango 0.219) }\end{array}$} & 0,000 \\
\hline $\begin{array}{l}\text { - castellanohablante } \\
\text { - bilingüe }\end{array}$ & $\begin{array}{l}0,609 \\
0,391\end{array}$ & $\begin{array}{l}\text { - castellanohablante } \\
\text { - bilingüe }\end{array}$ & $\begin{array}{l}0,609 \\
0,390\end{array}$ & $\begin{array}{l}0,000 \\
0,000\end{array}$ \\
\hline \multicolumn{2}{|l|}{$\begin{array}{l}\text { Tipo de texto } \\
\text { (rango } 0.208 \text { ) }\end{array}$} & \multicolumn{2}{|l|}{$\begin{array}{l}\text { Tipo de texto } \\
\text { (rango }(0,206)\end{array}$} & 0.000 \\
\hline - narrativo & 0,583 & - narrativo & 0,583 & 0,003 \\
\hline - dialogal & 0,544 & - dialogal & 0,534 & 0,409 \\
\hline - expositivo & 0,500 & - descriptivo & 0,513 & 0,565 \\
\hline - descriptivo & 0,486 & - expositivo & 0,484 & 0,658 \\
\hline - argumentativo & 0,375 & - argumentativo & 0,377 & 0,010 \\
\hline \multicolumn{2}{|l|}{$\begin{array}{l}\text { Tonicidad } \\
\text { (rango 0.197) }\end{array}$} & \multicolumn{2}{|l|}{$\begin{array}{l}\text { Tonicidad } \\
\text { (rango 0.197) }\end{array}$} & 0.001 \\
\hline $\begin{array}{l}\text { - sílaba postónica } \\
\text { - sílaba tónica } \\
\text { - sílaba postónica }\end{array}$ & $\begin{array}{l}0,598 \\
0,514 \\
0,401\end{array}$ & $\begin{array}{l}\text { - sílaba postónica } \\
\text { - sílaba tónica } \\
\text { - sílaba pretónica }\end{array}$ & $\begin{array}{l}0,597 \\
0,514 \\
0,407\end{array}$ & $\begin{array}{l}0,001 \\
0,591 \\
0,001\end{array}$ \\
\hline \multicolumn{2}{|l|}{$\begin{array}{l}\text { Modo de vida } \\
\text { (rango 0.191) }\end{array}$} & \multicolumn{2}{|l|}{$\begin{array}{l}\text { Modo de vida } \\
(\text { rango 0.190) }\end{array}$} & 0.020 \\
\hline - trabajo & 0,584 & - trabajo & 0,584 & 0,069 \\
\hline - ocio & 0,524 & - ocio & 0,523 & 0,336 \\
\hline - familia & 0,393 & - familia & 0,394 & 0,007 \\
\hline \multicolumn{2}{|c|}{$\begin{array}{l}\text { Run set up 114, Run down } 195 \\
\text { Log likelihood }{ }^{23}=-665.709 \\
\text { Maximum possible likelihood }=-573.987 \\
\chi^{2}(\mathrm{gl} 1185)=983.445 \\
\text { significación estadística, valor } \mathrm{p}=0.000\end{array}$} & \multicolumn{3}{|c|}{$\begin{array}{l}\text { Coeficiente log-odds }=-2.231 \\
\text { Error estándar }=0,480 \\
\text { Estadístico de Wald }=21,628 \\
\text { gl (1) } \\
\text { significatividad }=0,000\end{array}$} \\
\hline
\end{tabular}

Ambos análisis de regresión corroboran que son los factores sociales y estilísticos los de mayor incidencia en la variación sociolingüística del yeísmo. Según Labov (1972: 230-231) estamos ante un patrón sociolingüístico denominado 'marcador', puesto que intervienen esencialmente variables sociales (edad, residencia y sexo) y factores estilísticos (campo o tema de conversación, tenor-edad, tenor-estatus y tenor-proximidad).

23 El logaritmo de verosimiltud (Log. Likelihood) es el resultado de una prueba de razón de verosimilitud que indica la adecuación de la variante yeísta al modelo estadístico. 
Valoramos a continuación y de forma más detallada los resultados del cálculo probabilístico:

- El proceso de desfonologización queda favorecido, mayoritariamente, por los factores siguientes: estrato generacional joven (20-34 años), cuando se habla sobre temas cotidianos, si los interlocutores se sienten iguales o solidarios, si residen en la ciudad de Valencia o en la comarca Huerta Oeste, y si pertenecen al género femenino. Por su parte, mantienen la pronunciación lateral de $[K]$ o retrasan el proceso de deslateralización los mayores de 55 años, cuando se tratan temas técnicos, si residen en la comarca Huerta Norte, y si pertenecen al sexo masculino. Los resultados sociológicos obtenidos corroboran la primera y la segunda hipótesis de trabajo planteadas.

- También cabe destacar el importante valor explicativo y predictivo que ofrecen los factores estilísticos: tema de conversación y relación emisor-receptor (tenor-edad, tenor-estatus y, en menor medida, tenor-proximidad y tipo de texto). Parece evidente que el proceso de deslateralización queda favorecido por la interacción espontánea: tópicos cotidianos, cierta solidaridad e igualdad entre interlocutores así como discurso narrativo y dialogal.

- A pesar de que se trata de un fenómeno de nivel fónico, la incidencia de los factores lingüísticos queda debilitada en este proceso, pues solo la vocal anterior i- facilita el yeísmo. La posición de los articuladores en la vocal anterior (i) parece favorecer la pronunciación fricativa o aproximante. El resto de vocales anteriores no influye de forma relevante en el mantenimiento o deslateralización de $/ K /$. Por su parte, la sílaba tónica o átona donde aparece el segmento muestra escasa incidencia en el proceso fónico.

- Otras variables sociales que muestran cierta incidencia en el proceso de desfonologización son el nivel sociocultural y la lengua habitual de los hablantes, si bien con rangos de menor valor: 0.248 y 0.218 , respectivamente. No obstante, los individuos de nivel sociocultural bajo y los castellanohablantes ofrecen pesos probabilísticos con valor explicativo y predictivo importante. La tercera hipótesis de trabajo, relacionada con la aportación de los hablantes bilingües al mantenimiento de la oposición entre ambos fonemas no se corrobora completamente, pues tanto el rango señalado (0.218) como la proporción de bilingües que son distinguidores $(60.0 \%)$ no confirman de forma taxativa el papel que desempeñan los hablantes bilingües, hecho que puede interpretarse como una convergencia lingüística fónica y progresiva del castellano sobre el valenciano. 
- Finalmente, conviene tomar en consideración las variables excluidas en el análisis de regresión lineal por su escaso o nulo valor explicativo. Si bien el orden de eliminación no coincide exactamente en los modelos matemático-estadísticos de ambos programas, tanto la categoría gramatical de la palabra como la fase de la entrevista semidirigida no aportan valor explicativo ni predictivo alguno; asimismo, la estructura acentual de la palabra (aguda/llana/ esdrújula), la posición del segmento (interior de palabra, sinalefa o posición inicial/final) y la vocal posterior muestran una incidencia reducidísima.

Por su parte, el programa informático SPSS obtiene el gráfico de grupos observados y predichos así como la curva ROC (figura 11); esta curva ofrece una medida de la capacidad predictora de este modelo obtenida por contraste entre su sensibilidad (susceptibilidad) y el complementario de la especificidad ${ }^{24}$ :

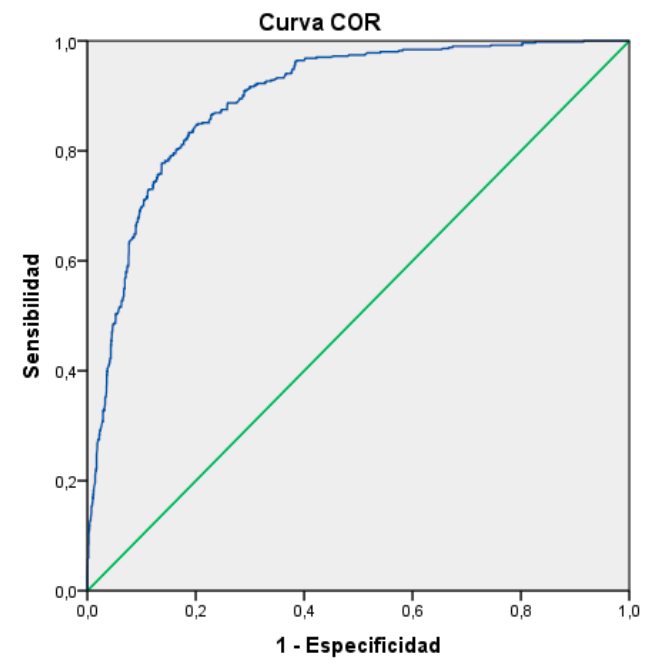

Los segmentos de diagonal se generan mediante empates.

Figura 11. Capacidad predictora del análisis multivariante (91.2\%)

24 La sensibilidad representa la relación entre la probabilidad de que un valor 1 sea predicho como 1 (verdaderos positivos) y la especificidad la de que los valores 0 que se predigan como 1 (falsos positivos). Cuanto más alejada está la curva de la diagonal, mejor ajuste. Cuanto más cerca está de la esquina superior izquierda, mejor ajuste. 


\section{Área bajo la curva}

Variable(s) de resultado de prueba: Probabilidad pronosticada

\begin{tabular}{|c|c|c|c|c|}
\hline \multirow{2}{*}{ Área } & \multirow{2}{*}{ Error estándar } & \multirow{2}{*}{$\begin{array}{l}\text { Significación } \\
\text { asintótica }^{\mathrm{b}}\end{array}$} & \multicolumn{2}{|c|}{$95 \%$ de intervalo de confianza asintótico } \\
\hline & & & Límite inferior & Límite superior \\
\hline ,912 & ,007 &, 000 & ,898 & ,925 \\
\hline
\end{tabular}

En este cálculo, el valor relevante es el mostrado en área. Según la curva ROC, esta modelización predice correctamente el 91.2\% de los casos; es decir, el índice de exactitud de predicción del modelo obtenido es muy alto teniendo en cuenta que se consideran modelos aceptables a partir del $75 \%$.

Como cierre de este análisis estadístico cabe señalar que el programa informático SPSS ofrece muchas más posibilidades de análisis cuantitativos que el modelo Goldvarb; además, permite configurar y personalizar cada análisis de un modo específico y adecuado a las necesidades de cada investigador. Algunos autores (Johnson 2009, Roy 2011) señalan las limitaciones del programa Goldvarb $X$, especialmente, la incapacidad para manejar los knock out y algunos aspectos técnicos relacionados con el modo de implementación del modelo de regresión logística binomial.

\subsection{PeRCEPCIÓN DE LOS ALÓFONOS}

Llegados a este punto solo nos resta evaluar los resultados de las pruebas de fonética perceptiva. Recuerde el lector la advertencia hecha a los jueces: desligar la ortografía de la palabra del sonido percibido. El estímulo recibido en las diez frases supone un total de doce casos de $[K]$ y ocho de [j]. Por otra parte, y desde la perspectiva sociolingüística, resultará muy productivo conocer qué individuos actúan como líderes en la no discriminación acústica de ambos fonemas y comparar sus características con las ya señaladas por los datos macrosociales del análisis probabilístico anterior.

Mostramos, en primer lugar, los resultados de la prueba general. Los valores obtenidos señalan que trece de ellos (54.2\%) son distinguidores y el resto $(45.8 \%)$ lo son a veces en mayor o menor grado. Los subgrupos sociales a los que pertenecen estos distinguidores son: $53.8 \%$ hombres y $46.2 \%$ mujeres; $61.5 \%$ bilingües y $38.5 \%$ castellanohablantes; $53.8 \%$ reside en pueblos del área metropolitana y $46.2 \%$ en la ciudad de Valencia. A continuación se ofrecen los resultados globales en el gráfico 2 . 


\begin{tabular}{|c|c|c|c|c|}
\hline & & \multicolumn{2}{|c|}{ categoría percibida } & \multirow{2}{*}{$\mathrm{n}^{\mathrm{o}}$ casos } \\
\hline & & $\mid K /$ & $/ \mathrm{j} /$ & \\
\hline \multirow{4}{*}{ 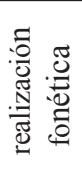 } & \multirow{2}{*}[\kappa]{} & 198 & 90 & 288 \\
\hline & & $68,75 \%$ & $31,25 \%$ & \\
\hline & \multirow{2}{*}{ [j] } & 49 & 143 & 192 \\
\hline & & $25,52 \%$ & $74,48 \%$ & \\
\hline
\end{tabular}

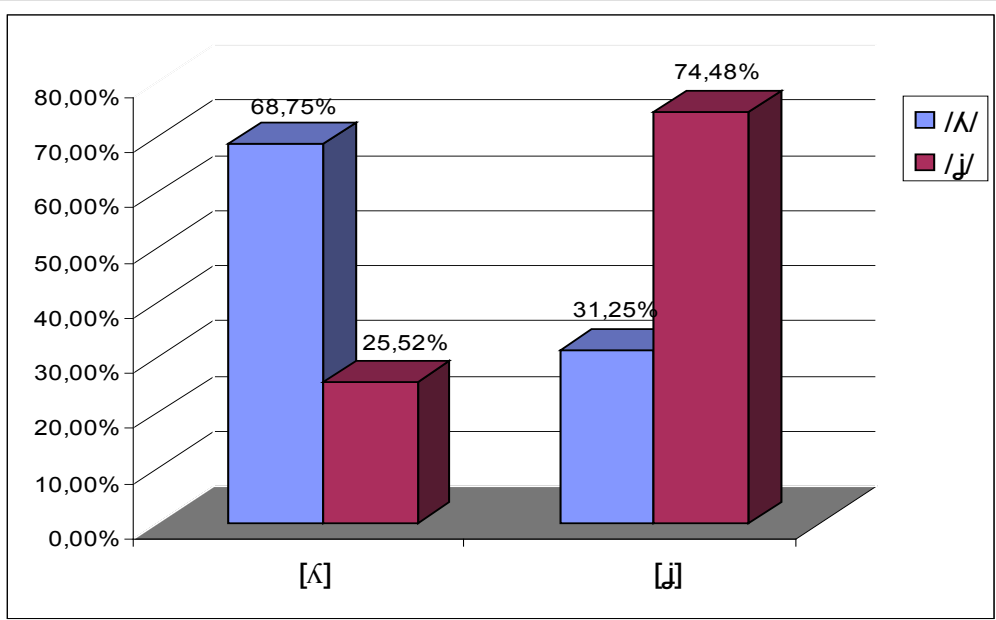

Gráfico 2. Percepción discriminatoria de los alófonos. Prueba general

Estos datos nos permiten algunas consideraciones:

- Si comparamos la proporción de yeísmo en las entrevistas semidirigidas (24.1\%) con la percibida en la prueba $(31.25 \%)$, se observa que la ambigüedad en la discriminación fónica es superior. Ello puede estar motivado por diversas causas, entre ellas, la transferencia yeísta progresiva del castellano hacia el valenciano, así como la aceptabilidad social del fenómeno.

- La confusión acústica de alófonos es relevante pues al menos una cuarta parte de ellos no se discrimina, hecho que corrobora la cuarta hipótesis de trabajo. Esta confusión resulta más abundante en la sustitución de $[\Lambda]$ por $/ \mathrm{j} /(31.25 \%)$ y muestra una evolución progresiva del yeísmo.

- Los casos percibidos como yeístas corresponden mayoritariamente a castellanohablantes (57.8), mujeres $(55.6 \%)$, residentes en la ciudad $(53.3 \%)$, jóvenes $(52.2 \%)$ y adultos $(42.2 \%)$. Se confirma de nuevo el liderazgo de jóvenes y mujeres en este proceso de deslateralización. 
- Finalmente, estos resultados confirman que la oposición fonológica entre las consonantes palatal lateral y palatal fricativa-aproximante responde a una situación de variación estable del yeísmo en esta comunidad de habla, si bien algunos factores sociales promocionan un proceso de cambio lingüístico.

Por su parte, los resultados de la prueba específica con los jueces universitarios señalan que el $47.5 \%$ de estos jóvenes son distinguidores y el resto $(52.5 \%)$ lo son ocasionalmente, en mayor o menor medida. La estratificación de los diecinueve distinguidores totales es la siguiente: $52.6 \%$ mujeres y $47.4 \%$ hombres; $57.9 \%$ bilingües y $42.1 \%$ castellanohablantes; $63.2 \%$ reside en pueblos del área metropolitana y $36.8 \%$ en la ciudad de Valencia.

Los resultados de esta prueba (gráfico 3) muestran la identificación y confusión mostrada entre la realización fonética del emisor y la categoría percibida:

\begin{tabular}{|c|c|c|c|c|}
\hline & & \multicolumn{2}{|c|}{ categoría percibida } & \multirow{2}{*}{$\mathrm{n}^{\circ} \operatorname{casos}$} \\
\hline & & $\mid K /$ & /j/ & \\
\hline \multirow{4}{*}{ 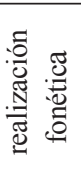 } & \multirow{2}{*}[\Lambda]{} & 291 & 189 & 480 \\
\hline & & $60,63 \%$ & $39,38 \%$ & \\
\hline & \multirow{2}{*}{ [j] } & 133 & 187 & 320 \\
\hline & & $41,56 \%$ & $58,44 \%$ & \\
\hline
\end{tabular}

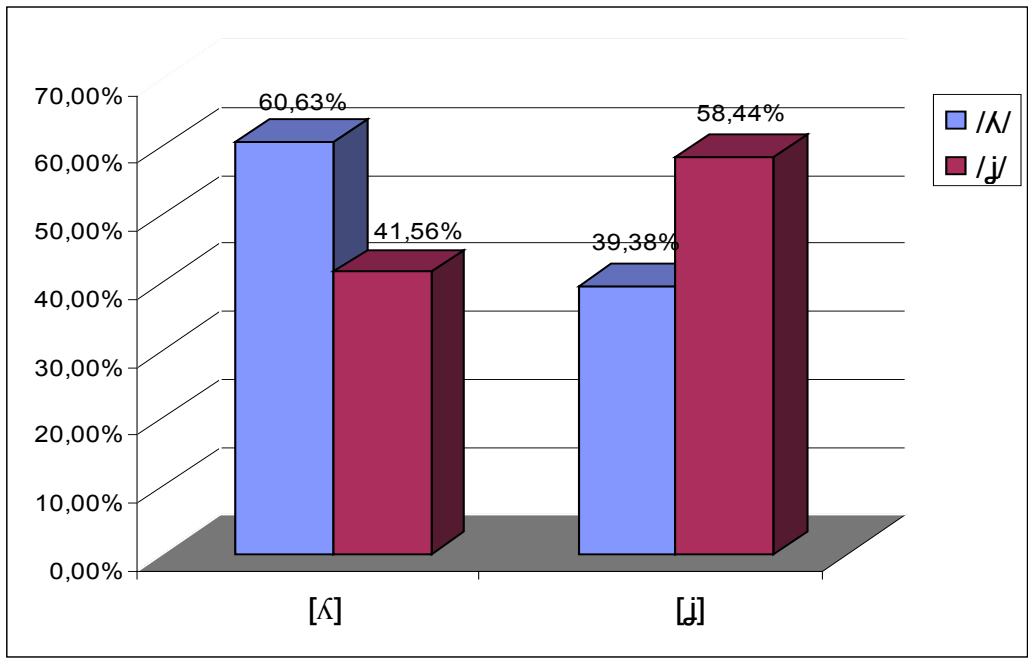

Gráfico 3. Percepción discriminatoria de los alófonos. Prueba específica 
Si analizamos la respuesta de los jueces jóvenes en la discriminación fónica, se observa que han prestado una mayor atención en esta prueba (identidad $\mid K /-[K]=60.63 \%$ ) que la mostrada en la producción natural de las entrevistas semidirigidas $(/ K / \rightarrow[K]=47.0 \%)$; ello es lógico al tratarse de jóvenes universitarios. No obstante, el grado de confusión fónica o ambigüedad es muy relevante, alrededor del $40 \%$; este hecho, al tratarse de individuos bien formados académicamente, podría plantear si es posible discriminar inequívocamente dichos sonidos. Y la respuesta parece positiva dado que diecinueve de los cuarenta jueces los han diferenciado completamente. Todos estos datos indican que muchos hablantes no son, aparentemente, conscientes de la variación y del cambio fónicos que se está operando en el castellano de nuestra comunidad de habla; y, en nuestra opinión, ello podría ser consecuencia de la escasa atención prestada a la pronunciación del español en las etapas escolares de Educación Primaria y Secundaria (competencia ortoépica).

Por último, al comparar el conjunto de resultados con los de la prueba general anterior, cabe destacar el incremento de la deslateralización que experimenta el fonema $/ K /$ pues pasa del $68.75 \%$ al $60.63 \%$, dato que se corresponde con el incremento del yeísmo en los jóvenes (del $31.25 \%$ al $39.38 \%$ ). Estos valores confirman el peso que este grupo generacional está ejerciendo en la evolución del proceso fonológico.

\section{CONCLUSIÓN}

Es el momento de comprobar el grado de cumplimiento de los objetivos formulados así como la corroboración o no de las hipótesis planteadas. Para ello revisamos los resultados más relevantes que ha aportado esta investigación sobre el yeísmo en la comunidad de habla bilingüe castellanocatalán de Valencia.

Como apuntábamos en la Introducción, existe amplia información sobre el dinamismo del fenómeno yeísta en diversas zonas del ámbito español, pero una somera revisión de los atlas dialectales peninsulares y de los trabajos empíricos citados demuestra una gran variación en su realización fonética, incluso dentro de una misma área geográfica. Ante esta realidad es necesario clarificar, como señala Rost Bagudanch (2014: 142), si las diversas realizaciones fonéticas son posibles de forma general o si cabe hablar de variantes exclusivas o específicas de un territorio determinado. 
Tanto los mecanismos de naturaleza fonético-fonológica como las variables sociolingüísticas y el contacto de lenguas en nuestra comunidad de habla nos han permitido interpretar en qué fase se encuentra actualmente el proceso de deslateralización del fonema $/ K /$. Atendiendo a los resultados obtenidos nos encontramos en la segunda fase apuntada por Moreno Fernández (2004: 987): yeísmo con variación, puesto que el grado de mantenimiento de la lateral palatal es del $75.9 \%$ y las variantes yeístas suponen el $24.1 \%$. Sin embargo, esta evaluación en tiempo aparente puede evolucionar y favorecer un proceso progresivo de desfonologización en tiempo real.

Es evidente que nos encontramos ante un hecho producto de múltiples causas y es necesario jerarquizar su incidencia. Tal como ha sucedido en otros procesos dinámicos condicionados, las primeras causas son de índole sociolingüística (Labov 2001: 97) y posterioremente actúa el contexto fónico. Los resultados de nuestra investigación muestran un alto índice de exactitud en la predicción (91.2\%) y señalan que el yeísmo queda favorecido por diferentes grupos de factores, que señalamos a continuación según su orden de incidencia:

a) Factores sociales: la edad y el sexo de los hablantes muestran un valor explicativo y predictivo determinantes en la variación lingüística del fonema $/ K /$ en esta comunidad de habla bilingüe. Mientras la generación joven (20-34 años) y el sexo femenino parecen promocionar un proceso de cambio en marcha, los mayores de 55 años y el género masculino ofrecen mayor resistencia a la pérdida de esta oposición fonológica. Quedan corroboradas, pues, la primera y segunda hipótesis de trabajo. Asumiendo, desde un punto de vista comparativo, que cada comunidad de habla responde de manera distinta al proceso que estamos investigando, nuestros resultados coinciden con los obtenidos en otras comunidades de habla bilingüe castellano-catalán: Gandia (área semiurbana) y Barcelona (área urbana).

Es cierto que la edad aporta una dimensión crucial al proceso de cambio, pero no es suficiente. Sin embargo, la combinación de edad y género son relevantes; como señala Labov (2001: 295) al tratar la intersección de sexo, edad y social: "In many cases, sound changes involve a simultaneous movement along both axes, gender and age" (En muchos casos, los cambios fónicos entrañan un movimiento simultáneo de ambos ejes, sexo y edad).

Por otra parte, en nuestro intento de descubrir quiénes actúan como líderes en este proceso dinámico se observa que los resultados de estadística descriptiva, los de estadística inferencial y los de fonética perceptiva general muestran una tendencia mayoritaria de mujeres y jóvenes. 
b) También los factores estilísticos ofrecen relevancia en el análisis sociolingüístico. En este modelo de variación estable muestran incidencia los rasgos contextuales de espontaneidad en la interacción comunicativa: hablar de temas cotidianos, ser más joven que el interlocutor, pertenecer a la red social o considerarse una persona de mayor prestigio que el otro; es decir, cuando el grado de atención prestado al habla es mínimo.

c) Otros factores sociológicos que también ofrecen valores explicativo y predictivo en esta caso son la residencia, el nivel sociocultural y la lengua habitual. El primero es el de mayor incidencia: son más yeístas quienes viven en la ciudad, hecho que corrobora el carácter urbano del fenómeno, y aquellos que habitan en la comarca de mayor inmigración dentro del área metropolitana. Por su parte, las otras dos variables ofrecen menor contribución pues existe menos diferencia entre sus variantes; son el sociolecto bajo y los castellanohablantes quienes favorecen la desfonologización pero con pesos ajustados; lo mismo sucede en el caso opuesto, ni el sociolecto alto ni los hablantes bilingües promueven claramente el mantenimiento de la distinción fonemática. Se confirma parcialmente la tercera hipótesis de trabajo, pues parece evidente la transferencia del yeísmo castellano hacia la otra lengua en contacto.

d) La conjunción de factores sociales y estilísticos permite valorar este caso de variación con un patrón sociolingüístico de 'marcador'.

e) En cuanto a la acción del contexto fónico, solo un factor interviene de forma clara en este caso de variación: la vocal anterior i (ICV). El resto de vocales anteriores no influye sustancialmente a favor ni en contra, y recordemos que las vocales posteriores ya fueron excluidas en los primeros pasos del análisis de regresión.

f) Finalmente, los resultados de las pruebas de fonética perceptiva señalan una relevante confusión acústica, tanto en la percepción de $[\Lambda] \rightarrow / j /$ como en la de [j] $\rightarrow / K /$, datos que corroboran la cuarta hipótesis de trabajo. Si bien esta ambigüedad en la discriminación fónica facilita a largo plazo la sustitución de un fonema por otro, en la actualidad la proporción de distinguidores totales facilita la variación estable del yeísmo.

Así pues, podemos concluir que la consonante lateral palatal $[K]$ mantiene sus rasgos articulatorios en la producción acústica de gran parte de los hablantes de esta comunidad de habla (75.9\%) pero va perdiendo, como en otras áreas peninsulares, su rasgo de lateralidad para confluir con la palatal fricativa [j] $y$, en menor medida, con la semivocal aproximante palatal [j]. Ello viene motivado, fundamentalmente, porque al no ser necesario maximizar la distintividad, se minimiza el esfuerzo de producción. 


\section{REFERENCIAS BIBLIOGRÁFICAS}

Alarcos, Emilio. 1971. Fonología Española. Madrid: Gredos.

Ariza, Manuel. 1994. Sobre fonética histórica del español. Madrid: Arco Libros.

Calsamiglia, Helena y Amparo Tusón. 1999. Las cosas del decir: manual de análisis del discurso. Barcelona: Ariel.

Cano Aguilar, Rafael. 2004. Cambios en la fonología del español durante los siglos XVI y XVII. En Rafael Cano (coord.). Historia de la lengua española, pp. 825-857. Barcelona: Ariel.

Caravedo, Rocío. 2013. Yeísmo y distinción en el contexto social peruano. Reexamen de la cuestión. En Rosario Gómez e Isabel Molina (eds.). Variación yeísta en el mundo hispánico, pp. 257-294. Madrid: Iberoamericana.

2014. Percepción y variación lingüistica. Enfoque sociocognitivo. Madrid/ Frankfurt: Iberoamericana/Vervuert.

Cutillas, Juan Antonio. 2003. Teoría lingüística de la Optimidad. Murcia: Universidad de Murcia.

Dubert, Francisco. 2013. El yeísmo y el fortalecimiento de /j/ en Galicia. En Rosario Gómez e Isabel Molina (eds.). Variación yeísta en el mundo hispánico, pp. 39-57. Madrid: Iberoamericana.

Frago, Juan Antonio. 1993. Historia de las hablas andaluzas. Madrid: Arco Libros.

Guitarte, Guillermo. 1983. Notas para la historia del yeísmo. En Guillermo Guitarte. Siete estudios sobre el español de América, pp. 127-146. México: UNAM.

Guy, Gregory R. 1997. Violable is variable: Optimality theory and linguistic variation. Language Variation and Change 9: 333-347.

Guy, Gregory R. y Charles Boberg. 1997. Inherent variability and the Obligatory Contour Principle. Language Variation and Change 9: 149-164.

Hernández, Juan M. y Manuel Almeida. 2005. Metodología de la investigación sociolingüistica. Granada: Editorial Comares.

International Phonetic Association. 2005. Handbook of the International Phonetic Association: A guide to the use of the International Phonetic Alphabet. Cambridge: C.U.P. Disponible en $<$ http://liceu.uab.es/ joaquim/phonetics/fon_transcr/transcripcion_fonetica. html\#AFI> [Consulta 21/09/2015].

JimÉnez, Jesús y Maria-Rosa Lloret. 2015. Semivocals en la cruïlla: enfortiment i lenició en els marges sil.làbics. En F. Sánchez, A. Martín y A. Piquer (eds.). Actes del XVI Col•loqui Internacional de Llengua i Literatura Catalanes, vol. 2, pp. 527-542. Barcelona: Publicacions de l'Abadia de Montserrat.

JoHNSON, DANIEL. 2009. Getting off the Goldvarb Standard: Introducing Rbrul for Mixed-Effects Variable Rule Analysis. Language and Linguistics Compass 3-I: 359-383.

Labov, William. 1972. Sociolinguistic Patterns. Philadelphia: University of Pennsylvania Press. Trad. Española. 1983. Modelos sociolingüísticos. Madrid: Cátedra.

2001. Principles of Linguistic Change. Vol. 2: Social Factors. Massachusetts: Blackwell.

LinDBLOM, BJöRN. 1990. Explaining phonetic variation: A sketch of the H\&H Theory. En W. J. Hardcastle y A. Marchal (eds.). Speech Production and Speech Modelling, pp. 403-439. Dordrecht: Kluwer Academic Publishers.

Lloret, Maria-Rosa. 2002. Canvi lingüístic i variació fònica. En Ma $\mathrm{M}^{\mathrm{a}}$. A. Cano et al. (eds.). Les claus del canvi lingüistic, pp. Alicante: Institu Interuniversitari de Filologia Valenciana.

Martín Butragueño, Pedro. 2002. Variación fonológica y teoría fonológica. México: El Colegio de México. 
98: $11-38$.

2012. Variación y cambio lingüístico en el español mexicano, Español Actual

2013. Estructura del yeísmo en la geografía fónica de México. En Rosario Gómez e Isabel Molina (eds.). Variación yeísta en el mundo hispánico, pp. 169-206. Madrid: Iberoamericana.

Martínez Celdrán, Eugenio y Ana María Fernández Planas. 2007. Manual de fonética española. Articulaciones y sonidos del español. Barcelona: Ariel.

Martínez Martín, Francisco M. 1983. Fonética y sociolingüística en la ciudad de Burgos. Madrid: Consejo Superior de Investigaciones Científicas.

MARTINET, ANDRÉ. 1974. Economía de los cambios fonéticos. Tratado de fonología diacrónica. Madrid: Gredos.

Molina Martos, Isabel. 1997. Dos cambios fonético-fonológicos en el español peninsular: aspectos geográficos y sociales. En Francisco Moreno (ed.). Trabajos de sociolingüistica hispánica, pp. 69-91. Alcalá: Universidad de Alcalá de Henares.

2013. Yeísmo madrileño y convergencia dialectal campo/ciudad. En Rosario Gómez e Isabel Molina (eds.). Variación yeísta en el mundo hispánico, pp. 93-110. Madrid: Iberoamericana.

Moratal, Vicente. 2011. Estudio sincrónico y contrastivo sobre el yeísmo en Gandía: enfoque variacionista y sociolingüístico. Ianua. Revista Philologica Románica 11: 135-154.

Moreno Fernández, Francisco. 2004. Cambios vivos en el plano fónico del español: variación dialectal y sociolingüística. En Rafael Cano (coord.). Historia de la lengua española, pp. 973-1009. Barcelona: Ariel.

2012. Sociolingüistica cognitiva. Proposiciones, escolios y debates. Madrid: Iberoamericana.

Morris, Richard E. 1998. Stylistic Variation in Spanish Phonology. Tesis. The Ohio State University. Disponible en http://roa.rutgers.edu/article/view/302 [Consulta 24/11/2015]

NaVArro Tomás, Tomás. 1964. La pronunciación en el ALPI. Hispania 47, 4: 716-721. 1990. Manual de pronunciación española. Madrid: CSIC.

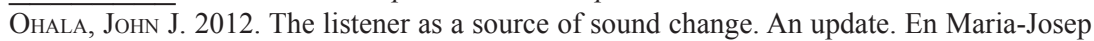
Solé and Daniel Recasens (eds.). The initiation of sound change. Perception, production, and social factors, pp. 21-35. Amsterdam: John Benjamins.

Paolillo, John C. 2001. Analyzing Linguistic Variation. Statistical Models and Methods. Stanford: CSLI Publications.

Penny, RalPh.2000.Variación y cambio en español. Madrid: Gredos.

2004). Evolución lingüística en la Baja Edad Media: evoluciones en el plano fónico. En Rafael Cano (coord.). Historia de la lengua española, pp. 593-612. Barcelona: Ariel

Prince, Alan and Paul Smolensky. 2004. Optimality Theory. Constraint Interaction in Generative Grammar. Oxford: Blackwell.

Quilis, Antonio. 1988). Fonética acústica de la lengua española. Madrid: Gredos.

1993. Tratado de fonética y fonología española. Madrid: Gredos.

Real Academia Española, Asociación de Academias de la Lengua española. 2005. Diccionario panhispánico de dudas. Madrid: Santillana Ediciones.

Robinson, John, Helen Lawrence and Sali Tagliamonte. 2001. GOlDVARB 2001. A multivariate analysis application for Windows. University of Cork: Department of Languages and Linguistics.

Rost Bagudanch, Assumpció. 2013. La transcripción fonética en estudios dialectales: propuestas en el caso del yeísmo. Revista de Filología Española XCIII, 1: 165-192. 
2014. Una panorámica del yeísmo: ¿un proceso acabado o en construcción? Revista Internacional de Lingüistica Iberoamericana 23: 141-163.

Roy, JosEPH. 2011. Sociolinguistics Statistics: The Intersection between Statistical Models, Sociolinguistic Theory and Empirical Data. Methods in Dialectology 14. University of Western Ontario. Publicado en http://www.uottawa.ca/ jroy042/papers/socio.stats.a.pdf [Consulta 24/06/2015]

Segura, Carles. 2003. Una cruilla lingüistica. Caracterització del parlar del Baix Vinalopó. Alcanat: Universitat d'Alacant.

Torres, Antonio et Alit. 2013. Estudio del yeísmo en el español de Barcelona a partir de materiales del PRESEEA. En Rosario Gómez e Isabel Molina (eds.). Variación yeista en el mundo hispánico, pp. 19-37. Madrid: Iberoamericana.

Villena, JuAn A. 2003. Restricciones de concurrencia entre las consonantes obstruyentes fricativas en los dialectos innovadores del español. Datos de la variación fonológica en el español de Andalucía. En Francisco Moreno et alii (eds.). Lengua, variación y contexto. Estudios dedicados a Humberto López Morales, pp. 907-922. Madrid: Arco Libros.

Visauta, Bienvenido. 2001. Análisis estadístico con SPSS para Windows. Estadística multivariante. Madrid: Mc Graw Hill. 